\title{
$\alpha 2 \delta$-2 Protein Controls Structure and Function at the Cerebellar Climbing Fiber Synapse
}

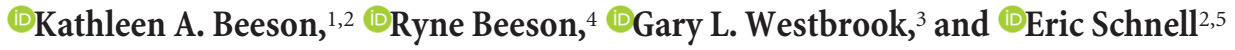 \\ ${ }^{1}$ Neuroscience Graduate Program, ${ }^{2}$ Department of Anesthesiology and Perioperative Medicine, ${ }^{3}$ The Vollum Institute, Oregon Health \& Science University, \\ Portland, Oregon 97239, ${ }^{4}$ Department of Aerospace Engineering, University of Illinois at Urbana-Champaign, Urbana, Illinois 61801, and ${ }^{5}$ Operative Care \\ Division, Portland VA Health Care System, Portland, Oregon 97239
}

$\alpha 2 \delta$ proteins (Cacna2d1-4) are auxiliary subunits of voltage-dependent calcium channels that also drive synapse formation and maturation. Because cerebellar Purkinje cells (PCs) predominantly, if not exclusively, express one isoform of this family, $\alpha 2 \delta$-2 (Cacna2d2), we used PCs as a model system to examine roles of $\alpha 2 \delta$ in excitatory synaptic function in male and female Cacna2d 2 knock-out (K0) mice. Whole-cell recordings of PCs from acute cerebellar slices revealed altered climbing fiber (CF)-evoked complex spike generation, as well as increased amplitude and faster decay of CF-evoked EPSCs. CF terminals in the KO were localized more proximally on PC dendrites, as indicated by VGLUT2 ${ }^{+}$immunoreactive puncta, and computational modeling demonstrated that the increased EPSC amplitude can be partly attributed to the more proximal location of CF terminals. In addition, CFs in KO mice exhibited increased multivesicular transmission, corresponding to greater sustained responses during repetitive stimulation, despite a reduction in the measured probability of release. Electron microscopy demonstrated that mutant $\mathrm{CF}$ terminals had twice as many vesicle release sites, providing a morphologic explanation for the enhanced glutamate release. Though KO CFs evoked larger amplitude EPSCs, the charge transfer was the same as wild-type as a result of increased glutamate reuptake, producing faster decay kinetics. Together, the larger, faster EPSCs in the KO explain the altered complex spike responses, which degrade information transfer from PCs and likely contribute to ataxia in Cacna2d2 K0 mice. Our results also illustrate the multidimensional synaptic roles of $\alpha 2 \delta$ proteins.

Key words: alpha2delta proteins; CACNA2D2; calcium channel; climbing fiber; Purkinje cell

\section{Significance Statement}

$\alpha 2 \delta$ proteins (Cacna2d1-4) regulate synaptic transmission and synaptogenesis, but coexpression of multiple $\alpha 2 \delta$ isoforms has obscured a clear understanding of how various $\alpha 2 \delta$ proteins control synaptic function. We focused on roles of the $\alpha 2 \delta$ - 2 protein (Cacna2d2), the deletion of which causes cerebellar ataxia and epilepsy in mice and humans. Because cerebellar Purkinje cells (PCs) only express this single isoform, we studied excitatory climbing fiber synaptic function onto PCs in Cacna2d $2 \mathrm{KO}$ mice. Using optical and electrophysiological analysis, we provide a detailed description of the changes in PCs lacking $\alpha 2 \delta$-2, and provide a comprehensive mechanistic explanation for how functional synaptic phenotypes contribute to the altered cerebellar output.

\section{Introduction}

Synapses are indispensable to neural circuit function, yet our understanding of synapse formation and physiology in health

\footnotetext{
Received June 25, 2019; revised Dec. 18, 2019; accepted Jan. 7, 2020.

Author contributions: K.A.B., G.L.W., and E.S. designed research; K.A.B. and R.B. performed research; K.A.B., R.B., and E.S. analyzed data; K.A.B. wrote the first draft of the paper; K.A.B., G.L.W., and E.S. edited the paper; K.A.B. and E.S. wrote the paper.

This work was supported in part by the Department of Veterans Affairs, Veterans Health Administration, Office of Research and Development, Biomedical Laboratory Research and Development Merit Review Award I01-BX002949 (E.S.), a Department of Defense CDMRP Award W81XWH-18-1-0598 (ES), NIH T32NS007466 (K.A.B.), NIH R01NS080979 (G.L.W.), NINDS 1R21NS102948 (Dr. Ines Koerner and E.S.), NIH P30NS061800 (Dr. Sue Aicher), and OHSU Innovation Fund (E.S.) awards. The electron microscope was purchased with funds from the Murdock Charitable Trust awarded to Dr. Aicher. We thank Dr. Stefanie Kaech-Petrie of the OHSU Advanced Light Microscopy Core for assistance with imaging; Dr. Gail Mandel and Dr. John Sinnamon for expertise and use of laser capture equipment; the OHSU Gene Profiling/RNA and DNA Services Shared Resource for support with qPCR experiments; and Dr. Sue
}

and neurological disease is incomplete. Recently, $\alpha 2 \delta$ proteins (Cacna2d1-4) have been recognized as important regulators of synapse formation and plasticity (Dolphin, 2012). In addition to their roles in synaptic transmission as auxiliary subunits of voltage-dependent calcium channels (VDCCs) (Cantí et al.,

Aicher, James Carroll, and Jo Hill for the electron microscopy expertise. We would like to acknowledge Drs. Sergey Ivanov and Lino Tessarollo for generously providing the Cacna2d2 KO mice; Drs. Michael Häusser and Arnd Roth for necessary files and permission to use the NEURON model; and research associates Arielle Isakharov and Ada Zhang for outstanding technical support. We also thank Dr. Christopher Vaaga and Dr. Laurence Trussell for constructive comments on the manuscript. The contents of this manuscript do not represent the views of the U.S. Department of Veterans Affairs or the United States Government.

The authors declare no competing financial interests.

Correspondence should be addressed to Eric Schnell at schneler@ohsu.edu.

https://doi.org/10.1523/JNEUROSCI.1514-19.2020

Copyright $\odot 2020$ the authors 
2005; Hoppa et al., 2012), these proteins have multiple postsynaptic roles in driving synapse formation, trans-synaptic communication, and glutamate receptor function (Eroglu et al., 2009; Kurshan et al., 2009; Fell et al., 2016; Wang et al., 2016; Brockhaus et al., 2018; Chen et al., 2018; Geisler et al., 2019). Mutations in human $\alpha 2 \delta$ genes have been associated with epilepsy, movement disorders, and schizophrenia (Edvardson et al., 2013; Pippucci et al., 2013), and $\alpha 2 \delta-1 / 2$ proteins are the primary targets of the widely prescribed antiepileptic and analgesic, gabapentin (Gee et al., 1996; Brown and Gee, 1998; Gao et al., 2000). However, the roles of $\alpha 2 \delta$ proteins in controlling synaptic and network function at any given synapse are still elusive, due in part to expression of multiple isoforms in many neurons.

Purkinje cells (PCs), the primary output pathway from the cerebellar cortex, appear to exclusively and abundantly express the $\alpha 2 \delta$-2 isoform (Cacna2d2) (Barclay et al., 2001; Cole et al., 2005; Lein et al., 2007; Dolphin, 2012), thus providing an opportunity to determine how this protein contributes to synaptic transmission. Like the spontaneous 'ducky' mouse mutants $\left(d u^{2 j} / d u^{2 j}\right.$ or $\left.d u / d u\right)$, targeted deletion of $\alpha 2 \delta$-2 causes cerebellar ataxia, epilepsy and premature death (Barclay et al., 2001; Brodbeck et al., 2002; Ivanov et al., 2004; Donato et al., 2006), indicative of its importance in neurological function.

The global loss of $\alpha 2 \delta$-2 likely affects synapses throughout the brain. However, the climbing fiber (CF) to PC synapse has multiple distinctive features, including the mono-innervation of mature PCs by a single CF (Hashimoto et al., 2009) and presynaptic expression of vesicular glutamate transporter 2 (VGLUT2), allowing for the visualization of CF terminals and making this an ideal site to determine how $\alpha 2 \delta$ - 2 contributes to synaptic function. In contrast to PCs, the inferior olivary (IO) cells (from which CFs arise) predominantly express the $\alpha 2 \delta$ - 1 isoform, with low expression of $\alpha 2 \delta$-2/3 isoforms (Cole et al., 2005; Lein et al., 2007). Finally, CF activity drives complex spike (CpS) generation in PCs, which produces a high-fidelity error prediction signal important to the processing of motor coordination and learning (Yang and Lisberger, 2014; Heffley et al., 2018).

We combined structural and electrophysiological analysis of the CF to PC synapse in Cacna2d2 KO mice (Ivanov et al., 2004) to elucidate the contribution of $\alpha 2 \delta$-2 to excitatory synapse formation and transmission. Contrary to positive regulation of excitatory synaptogenesis by the $\alpha 2 \delta$ - 1 isoform (Li et al., 2004; Eroglu et al., 2009; Chen et al., 2018; Risher et al., 2018), loss of $\alpha 2 \delta-2$ increased functional synaptic innervation by CFs. $\alpha 2 \delta-2$ KO CFs had elevated glutamate release and clearance compared with wild-type (WT), resulting in profound deficiencies in the generation of $\mathrm{CpS}$ spikelets. Together, our studies demonstrate the critical role of $\alpha 2 \delta$ - 2 in proper CF-PC synapse organization and network function, and allude to the wide versatility of $\alpha 2 \delta$ proteins in synaptic transmission.

\section{Materials and Methods}

Animals. Cacna2d2 KO mice (Cacna2d2 ${ }^{\text {tm1Svi }}$, MGI = 3055290; generously supplied by Drs. Sergey Ivanov and Lino Tessarollo) were obtained as cryopreserved sperm and rederived via in vitro fertilization on a C57B/6J background. Breeding mice were kept heterozygous, and genotyping was performed using the following primers: forward 5 '-ACTGG TGGGCATCTTACAGC-3', reverse mutant 5'-AAAGAACGGAGCCG GTTG-3', reverse WT $5^{\prime}$-TGTTAGCGGGGAGGTCACTA-3'. This produced $\mathrm{a} \sim 700 \mathrm{bp}$ product from the $\mathrm{WT}$ allele and $\mathrm{a} \sim 550 \mathrm{bp}$ product from the mutant allele. Mice were born in the Mendelian ratio of 1:2:1; with WT mice having two copies of the intact Cacna2d2 gene, and KO mice as homozygous mutants. Because $\sim 50 \%$ of $\mathrm{KO}$ mice die prematurely (Ivanov et al., 2004), all experiments used male and female mice between p21-p30, when CF-PC synapses have reached maturity, but before significant loss of $\mathrm{KO}$ mice.

Cacna2d 2 deletion was validated, and Cacna2d isoform abundance were measured, using quantitative PCR from fresh-frozen tissues. Regions of the IO and the PC layer (PCL), including the proximal molecular layer, were microdissected by laser capture for pre- vs postsynaptic comparative analysis. Briefly, mice were deeply anesthetized by inhalation of $4 \%$ isoflurane followed by injection of $0.8 \mathrm{ml}$ of $2 \%$ avertin i.p. (Sigma-Aldrich) and rapidly decapitated. Brains were rapidly dissected, mounted in OCT medium (Tissue-Tek) on dry ice, and placed at $-20^{\circ} \mathrm{C}$ for cryosectioning. $25 \mu \mathrm{m}$ coronal sections from cerebellum and brainstem were collected on RNase-treated PEN membrane slides (Zeiss). Slides were then dehydrated through a succession of EtOH rinses (70\% EtOH 30 s, 100\% EtOH 30 s), and nuclei stained using $1 \mathrm{mg} / \mathrm{ml}$ Cresyl Violet in $100 \% \mathrm{EtOH}$ ( $1 \mathrm{~min})$. IO and PCL regions were identified based on anatomic criteria, and isolated using laser microdissection (Zeiss). Samples were resuspended in 20 $\mu \mathrm{l}$ of QIAzol Lysis Reagent (Qiagen) for $20 \mathrm{~min}$ at RT and stored at $-80^{\circ} \mathrm{C}$. RNA isolation and $\mathrm{qPCR}$ were performed by the Oregon Health \& Science University Gene Profiling/RNA and DNA Services Shared Resource. In brief, RNA was isolated using the Trizol/RNeasy hybrid protocol with QIAcube automation. SuperScript IV VILO Master Mix (Invitrogen) was used for reverse transcription with $636 \mathrm{pg}$ of input RNA per $20 \mu \mathrm{l}$ reaction. Following reverse transcription, cDNA was quantified and normalized for $7500 \mathrm{ng}$ of cDNA input for preamplification in 14 PCR cycles. A 1:4 dilution of the pre-amp reaction was used as input for qPCR. The TaqMan Universal master mix (Life Technologies) was used for the PCR, using a single master mix per TaqMan probe set for Cacna2d1 (Mm00486607_m1), Cacna2d2 (Mm01230564_g1), Cacna2d3 (Mm00486641_m1), Cacna2d4 (Mm01190080_m1), and ACTB (Mm04394036_g1) as the endogenous control. Data were acquired using Applied Biosystems QuantStudio 12K Flex Software v1.2.2 (Life Technologies) with settings set to default. Measurements are reported as either $\Delta \mathrm{Ct}$ values (difference in cycle time for gene of interest relative to $A C T B$, in which a higher $\Delta \mathrm{Ct}$ indicates lower relative expression) or mean fold difference, as

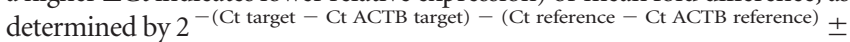
SEM.

Mice were maintained in facilities fully accredited by the Association for Assessment and Accreditation of Laboratory Animal Care and veterinary care was provided by Oregon Health \& Science University's Department of Comparative Medicine. All animal care and experiments were performed in accordance with state and federal guidelines, and all protocols were approved by the OHSU Institutional Animal Care and Use Committee.

Immunohistochemistry. Following deep anesthesia as described above, p21 Cacna2d2 KO and WT littermates were transcardially perfused with $5 \mathrm{ml}$ of PBS followed by $4 \%$ paraformaldehyde-PBS (PFA-PBS). Mice were decapitated, and brains were removed and postfixed for $24 \mathrm{~h}$ in $4 \%$ PFA-PBS. Cerebella were cut in sagittal sections at $50 \mu \mathrm{m}$ on a vibratome and stored in PBS at $4^{\circ} \mathrm{C}$. Sections containing vermis lobe VI were permeabilized with $0.4 \%$ Triton-PBS containing $10 \%$ normal goat serum for $1 \mathrm{~h}$ at room temperature, then stained with mouse antiCalbindin 1:20 (Neuromab \#73-452) and guinea pig anti-VGLUT2 1:200 (Synaptic Systems \#135404) at $4^{\circ} \mathrm{C}$ overnight. After rinsing, corresponding fluorescently labeled secondaries (Invitrogen) were applied at 1:400 and glass coverslips were mounted on glass slides with Fluoromount G (Sigma-Aldrich).

To image VGLUT2 ${ }^{+}$synapses, $6 \mu \mathrm{m} z$-stack images from the vermis lobe VI were acquired at $0.2 \mu \mathrm{m}$ intervals with a Zeiss LSM780 laser scanning confocal microscope at $40 \times$ magnification and $1024 \times 1024$ pixel density using ZEN software. This produced images of the entire thickness of the molecular layer, including the PC somata. Images were then analyzed in FIJI/ImageJ. VGLUT2 ${ }^{+}$puncta distribution/density were quantified from maximum projection images as distinct VGLUT2 ${ }^{+}$ puncta of at least $0.2 \mu \mathrm{m}^{2}$, after subtracting the background for increased contrast. For each punctum, the $y$-distance from the top of the PCL to the terminal was measured. Per image, a minimum of $100 \mu \mathrm{m}$ of linear PCL was quantified. VGLUT2 ${ }^{+}$puncta distributions were then binned into $10 \mu \mathrm{m}$ distances. VGLUT2 ${ }^{+}$puncta size and a second measure of density 
(from whole volume of tissue) were calculated using a masking feature in FIJI/ImageJ that captures puncta between $0.1-5 \mu \mathrm{m}^{2}$, and this was normalized to the length of PCL imaged to produce a measure of density per $\mu \mathrm{m}$ of PCL. Punctum distribution, density and size data were averaged from two or three sections per animal using five or six animals of each genotype. Slides were coded before imaging, and image acquisition and analysis were performed by investigators blinded to genotype. Sections were stained side by side with the same antibody mixtures, and imaging parameters were kept constant between samples.

Slice preparation and electrophysiology. KO or WT littermates were deeply anesthetized as described above, and transcardially perfused with ice-cold sucrose-based solution containing the following (in $\mathrm{mM}$ ): 87 $\mathrm{NaCl}, 2.5 \mathrm{KCl}, 1.25 \mathrm{NaH}_{2} \mathrm{PO}_{4}, 0.4$ ascorbate, $2 \mathrm{Na}$ pyruvate, $25 \mathrm{D}$-glucose, $25 \mathrm{NaHCO}_{3}, 75$ Sucrose, $7 \mathrm{MgCl}_{2}, 0.5 \mathrm{CaCl}_{2}$ (osmolarity adjusted to $300-305 \mathrm{mOsm}$ ) and equilibrated with $95 \% \mathrm{O}_{2}$ and $5 \% \mathrm{CO}_{2}$ gas mixture. Acute $300 \mu \mathrm{m}$ sagittal slices were cut from cerebellum using a vibratome (VT1200; Leica Microsystems), and incubated for $30 \mathrm{~min}$ in standard artificial CSF (aCSF) at $34^{\circ} \mathrm{C}$.

Whole-cell recordings were obtained using 1-3 $\mathrm{M} \Omega$ borosilicate glass pipettes filled with either K-gluconate or $\mathrm{CsCl}_{2}$-based internal solution. For current-clamp experiments, internal solution contained the following (in mM): $135 \mathrm{~K}$-gluconate, $10 \mathrm{HEPES}, 10 \mathrm{NaCl}, 1 \mathrm{MgCl}_{2}, 0.1 \mathrm{BAPTA}$, $0.1 \mathrm{CaCl}_{2}, 2 \mathrm{ATP}-\mathrm{Mg}$, and 10 phosphocreatine, $\mathrm{pH} 7.28$ adjusted with $\mathrm{KOH}$ (osmolarity adjusted to $289 \mathrm{mOsm}$ ). For voltage-clamp recordings, the internal solution contained the following (in mM): $100 \mathrm{CsMeSO}_{4}, 35$ CsCl, 15 TEA-Cl, $1 \mathrm{MgCl}_{2}$, 15 HEPES, 0.2 EGTA, 2 ATP-Mg, 0.3 TrisGTP, 10 phosphocreatine, and 2 QX-314, pH 7.3 adjusted with $\mathrm{CsOH}$ (osmolarity adjusted to $295 \mathrm{mOsm}$ ). External solution contained the following (in mM): $125 \mathrm{NaCl}, 25 \mathrm{NaHCO}_{3}, 1.25 \mathrm{NaH}_{2} \mathrm{PO}_{4}, 3 \mathrm{KCl}, 25$ Dextrose, $2 \mathrm{CaCl}_{2}, 1 \mathrm{MgCl}_{2}$ (osmolarity adjusted to $300 \mathrm{mOsm}$ ) and was continuously perfused via roller pump.

PCs from the vermis, lobe VI, were identified by soma size and location in the PCL using live infrared differential contrast microscopy on an upright Olympus microscope. Inhibition was blocked in all experiments by $10 \mu \mathrm{M}$ SR95531 (Tocris Bioscience). Whole-cell patch-clamp recordings were obtained in voltage-clamp mode with cell capacitance, series resistance and input resistance monitored in real time using intermittent $-10 \mathrm{mV}$ voltage steps. Signals were amplified with a MultiClamp 700B (Molecular Devices) amplifier and pipette capacitance was compensated for using MultiClamp software. Signals were low-pass filtered at $6 \mathrm{kHz}$ and sampled at $10 \mathrm{kHz}$, and digitized with a National Instruments analog-to-digital board. All recordings were acquired and analyzed using IgorPro-based (Wavemetrics) software. All recordings were performed at room temperature.

Climbing fiber-mediated EPSCs were evoked using theta or monopolar glass electrode stimulation in the granule cell layer $(0.1 \mathrm{~ms}, 0-100 \mathrm{~V}$ square pulses; 0.1 or $0.05 \mathrm{~Hz}$ stimulation frequency), placed $\sim 50 \mu \mathrm{m}$ from the PC, and the stimulation electrode position was adjusted as needed to obtain a CF response. CF responses were identified as large all-or-none EPSCs that appeared during incremental increases in stimulation intensity, with paired-pulse depression when stimulated with 2 pulses $50 \mathrm{~ms}$ apart. All cells were first recorded in voltage-clamp mode, where a hyperpolarizing step of $-10 \mathrm{mV}$ was applied to monitor cell capacitance, series resistance and input resistance. Series resistance was not compensated; cells with series resistance $>10 \mathrm{M} \Omega$, or a $>2 \mathrm{M} \Omega$ change in series resistance over the course of the experiment, were excluded.

For current-clamp experiments, PC resting membrane potential was measured by holding the cell in zero current mode, then a small amount of bias current $(\sim-130 \mathrm{pA})$ was injected to keep the cell near $-60 \mathrm{mV}$ for complex spike and current step experiments. Bridge balance was applied to compensate for pipette and series resistance throughout the recording. First, CFs were stimulated at $0.1 \mathrm{~Hz}$ and 10 consecutive sweeps of evoked complex spikes were recorded. Then with CF stimulation off, $500 \mathrm{~ms}$ steps of current injection from $-200 \mathrm{pA}$ to $1 \mathrm{nA}$ were delivered at least 5 times per step. Cells were returned to voltage-clamp mode to assess recording stability. For complex spike analysis, sweeps were averaged to measure the initial spike amplitude and rise rate. Spikelets were classified as rapid depolarizations $(>1000 \mathrm{~V} / \mathrm{s})$ that reached $+20 \mathrm{mV}$ from baseline, from which spikelet trough-to-peak amplitudes were measured. Area under the curve was measured by integrating the trace during the first $100 \mathrm{~ms}$ following stimulation.

For most voltage-clamp experiments, cells were held at $-70 \mathrm{mV}$ in the presence of $0.5 \mu \mathrm{M}$ NBQX (Tocris Bioscience) to maintain voltage clamp during CF EPSCs. Brief hyperpolarizing steps $(-10 \mathrm{mV})$ were delivered to monitor PC access and input resistance preceding each CF-evoked EPSC. 10 CF EPSC trials were averaged, and these averages were used to determine peak amplitude, $20-80 \%$ rise time and tau of decay (from single-exponential fits of the EPSC decay). Then, 10 paired-pulse responses with an interstimulus interval of $50 \mathrm{~ms}$ were collected, followed by $10 \mathrm{~Hz}$ trains of CF stimulation or drug wash-in experiments. For DL-TBOA experiments, baseline EPSCs were acquired at $0.05 \mathrm{~Hz}$ before $50 \mu \mathrm{M}$ DL-TBOA (Tocris Bioscience) was added to the bath. For kynurenic acid (KYN) experiments, aCSF excluded NBQX and PCs were held at $-20 \mathrm{mV}$ to maintain voltage-clamp during $0.1 \mathrm{~Hz} \mathrm{CF}$ stimulation. After acquiring baseline EPSCs, $1 \mathrm{~mm}$ KYN (Sigma-Aldrich) was added to the perfusate. Quantification of EPSC peak amplitude and tau of decay from drug wash-in experiments used averages from 10 sweeps before wash-on compared with 10 sweeps after $10 \mathrm{~min}$ of exposure to drug (For KYN effect: $\left(\right.$ EPSC $_{\text {Control }}-$ EPSC $\left._{\mathrm{KYN}}\right){ }^{\star} 100$; For TBOA effect: $\left.\left(\tau_{\mathrm{TBOA}}-\tau_{\text {Control }}\right){ }^{\star} 100\right)$. For asynchronous EPSC (aEPSC) experiments, aCSF was composed of $1.3 \mathrm{~mm} \mathrm{Sr}^{2+}$ in replacement of $\mathrm{Ca}^{2+}, 3.3 \mathrm{~mm}$ $\mathrm{Mg}^{2+}$, and NBQX was omitted. PCs were held at $-70 \mathrm{mV}$ and CFs were stimulated at $0.05 \mathrm{~Hz} . \sim 10$ trials were used for quantification of aEPSCs, which were sampled from a $500 \mathrm{~ms}$ window starting at $150 \mathrm{~ms}$ from CF stimulation, and selected manually. For data presentation, aEPSC traces were off-line box-filtered at $1 \mathrm{kHz}$. To estimate the readily releasable pool, cumulative CF response amplitudes were plotted, and the last third of the train was fit with a linear regression that was extrapolated to time 0 (Schneggenburger et al., 1999).

NEURON computational PC model. CF simulations were performed with NEURON version 7.7.0, using source code generously supplied by Dr. Michael Häusser (Roth and Häusser, 2001). The following model parameters were kept constant across all simulations: $R_{\mathrm{m}}=120.2 \mathrm{k} \Omega$ $\mathrm{cm}^{2}, C_{\mathrm{m}}=0.64 \mu \mathrm{F} / \mathrm{cm}^{2}$ and a residual uncompensated series resistance of $1 \mathrm{M} \Omega$. Because the model is based on recordings and dimensions of a p21 rat PC (Roth and Häusser, 2001), we normalized our WT measurements for CF distribution to the model cell as control, and adjusted the dendritic innervation by KO CFs based on our VGLUT2 ${ }^{+}$distribution as a relative decrease in length of coverage (i.e., $0.7 \times \mathrm{CF}$ length of control). CF EPSCs were simulated using 500 inputs of $1 \mathrm{nS}$ peak conductance (simulated as the sum of two exponentials for rise and decay) with a reversal potential of $0 \mathrm{mV}$ and a constant density per dendritic length distribution. Simulation time step was $10 \mu$ s for integration. Waveforms were created in IgorPro8 from simulation output to measure EPSC decay time constants by fitting with a single exponential.

Transmission electron microscopy (TEM). Animals were deeply anesthetized with isoflurane and avertin, as described above, and then transcardially perfused with $10 \mathrm{ml}$ of ice-cold heparin ( $1 \mathrm{k} \mathrm{USP} / \mathrm{ml}$; Novaplus) followed by freshly prepared $2 \%$ glutaraldehyde $2 \%$ paraformaldehyde in $0.1 \mathrm{M} \mathrm{PB}$ solution filtered with \#3 filter paper (VWR) and $\mathrm{pH}$ to 7.4. Brains were dissected and cerebella were blocked and postfixed for 30 $\min$ in $4 \%$ paraformaldehyde. Tissue was transferred to $0.1 \mathrm{M} \mathrm{PB}$ for storage at $4^{\circ} \mathrm{C}$ and $40 \mu \mathrm{m}$ sagittal slices of vermis lobe VI were made using a Leica microtome. Slices were collected in separate wells to assure TEM would be from slices $>100 \mu \mathrm{m}$ apart. PFA, glutaraldehyde and microtome blades were all from Electron Microscopy Sciences.

Tissue samples were coded before processing for TEM by a blinded investigator. Briefly, sections were incubated in $1 \%$ osmium tetroxide in PB for $30 \mathrm{~min}$, dehydrated through a graded series of ethanols, placed into propylene oxide for $30 \mathrm{~min}$, and then placed in 1:1 propylene oxide: EMBed resin (Electron Microscopy Sciences) rotating at room temperature overnight. Sections were then incubated in $100 \%$ resin for $2 \mathrm{~h}$, embedded between sheets of Aclar plastic, and incubated at $60^{\circ} \mathrm{C}$ for $48 \mathrm{~h}$. Cerebellum sections were then glued to resin blocks and ultrathin sections $(50 \mathrm{~nm}$ ) were collected onto 400 mesh copper grids (Electron Microscopy Sciences). The ultrathin sections were then counterstained with uranyl acetate and Reynolds lead citrate and examined using an FEI 
Tecnai 12 electron microscope and images were captured using an Advanced Microscopy Techniques digital camera.

CF terminals were imaged from the most highly innervated region of the molecular layer $(20-60 \mu \mathrm{m}$ from PC somata) and identified at $6800 \times$ magnification by the following criteria: proximity $(<3 \mu \mathrm{m})$ to PC primary dendrites, dense-packing of round vesicles, and when synaptic contacts were present, asymmetric Gray's type 1 excitatory synaptic markers. Images were taken at $18500 \times$ magnification and CF terminals with clearly delineated membranes that met the criteria described above were analyzed using Fiji/ImageJ software by a separate blinded investigator. Terminal area, total SV density, the length and number of synaptic contacts made by each terminal (as determined by the opposing postsynaptic density), and the number of SVs within $100 \mathrm{~nm}$ of each synaptic contact as a proxy for the readily releasable pool were measured. Quantifications from $\sim 10-15$ CF images per animal were averaged $(n=$ animals).

Statistics. Data were tested for Gaussian distribution using the Kolmogorov-Smirnov normality test with Dallal-Wilkinson-Lilliefor $p$-value. Differences between genotypes in VGLUT2 ${ }^{+}$puncta distribution and TEM total synaptic contacts/terminal were tested for significance using Kolmogorov-Smirnov test. For other nonparametric data, the MannWhitney test was used (i.e., $\mathrm{CpS}$ spikelet number). Immunofluorescence, TEM, and electrophysiology data with normal distributions were analyzed using Student's $t$ tests. Normalized and cumulative amplitude responses during repetitive CF stimulation were compared between genotypes using multiple $t$ tests with Holm-Sidak correction. For morphology data, multiple images per animal were averaged where $n=$ the number of mice. For electrophysiology, all experiments used at least four animals per genotype, where $n=$ the number of cells. Data were graphed in Prism GraphPad version 8 and are reported as the mean \pm SEM $\left({ }^{*} p<\right.$ $\left.0.05,{ }^{* *} p<0.01,{ }^{* * *} p<0.001,{ }^{* * * *} p<0.0001\right)$.

\section{Results}

\section{$\alpha 2 \delta$ - 2 controls PC spiking patterns in response to climbing} fiber activation

To examine how the loss of $\alpha 2 \delta$ - 2 affects cerebellar output, we performed whole-cell recordings from PCs in acutely prepared cerebellar slices from $\alpha 2 \delta-2 \mathrm{KO}$ mice and their WT littermates at p21-p30, after CF innervation has reached maturity (Hashimoto et al., 2009). We focally stimulated CFs in the granule cell layer and unitary CF-mediated EPSCs were identified by their large amplitude, all-or-nothing nature and paired-pulse depression (Dittman and Regehr, 1998; Hashimoto and Kano, 1998; Liu and Friel, 2008; Rudolph et al., 2011). CF-evoked CpSs were then recorded in current-clamp mode.

The voltage envelope of CpS waveforms was comparable between WT and $\mathrm{KO}$ (Fig. 1A; Integral of CpS between time 0-100 $\mathrm{ms}: \mathrm{WT}=0.96 \pm 0.06 \mathrm{~V} \cdot \mathrm{s}, n=10 ; \mathrm{KO}=0.81 \pm 0.06 \mathrm{~V} \cdot \mathrm{s}, n=$ $11 ; p=0.1$; unpaired Student's $t$ test), but the number of CpS spikelets was substantially reduced in $\mathrm{KO}$ PCs (Fig. $1 B$; WT $=$ $3.2 \pm 0.5, n=10 ; \mathrm{KO}=1.2 \pm 0.4, n=11 ; p=0.002$; MannWhitney). In addition, the few spikelets that did occur during the KO CpS were of lower trough-to-peak amplitude. All first spikelets in the WT were $>30 \mathrm{mV}$ compared with $75 \%$ in the $\mathrm{KO}$ (Fig. $1 C$ ), which is consistent with a lower probability of CpS transmission (Khaliq and Raman, 2005) in the $\alpha 2 \delta-2$ KO. Moreover, though subsequent spikelets were present in 2 of $11 \mathrm{KO}$ cells, none reached $30 \mathrm{mV}$ trough-to-peak amplitude (Mean KO spikelet $_{2}=16.5 \pm 5.7 \mathrm{mV}, n=2$; spikelet $_{3}=7.6 \mathrm{mV}, n=1$; spikelet $_{4}$ $=7.2 \mathrm{mV}, n=1$; spikelet $_{5}=6.5 \mathrm{mV}, n=1$ ). Despite the differences in CpS spikelet generation between genotypes, initial spike amplitudes (Fig. 1D) and rise rates were unchanged between WT and $\mathrm{KO}$ (Spike slope: $\mathrm{WT}=1790 \pm 230 \mathrm{~V} / \mathrm{s}, n=10 ; \mathrm{KO}=$ $1660 \pm 240 \mathrm{~V} / \mathrm{s}, n=11 ; p=0.69$; unpaired Student's $t$ test).

The altered $\mathrm{CpS}$ in KO PCs were not associated with changes in the intrinsic excitability of $\alpha 2 \delta$ - $2 \mathrm{KO}$ PCs as measured by their
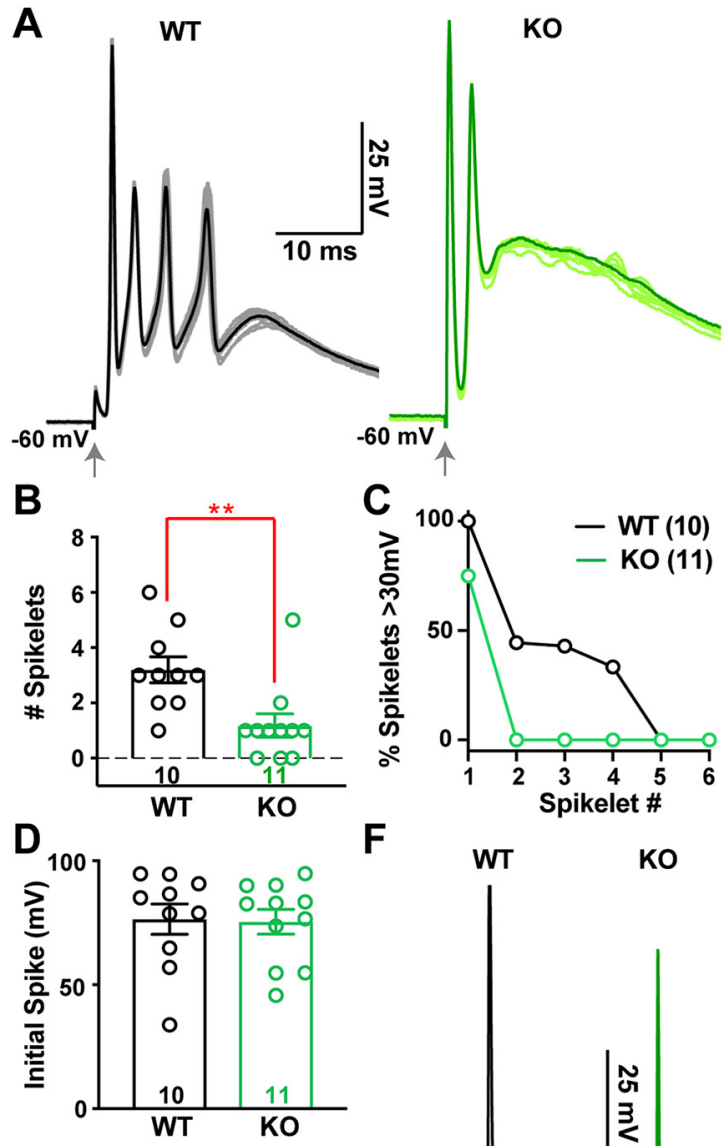

$\mathbf{F}$
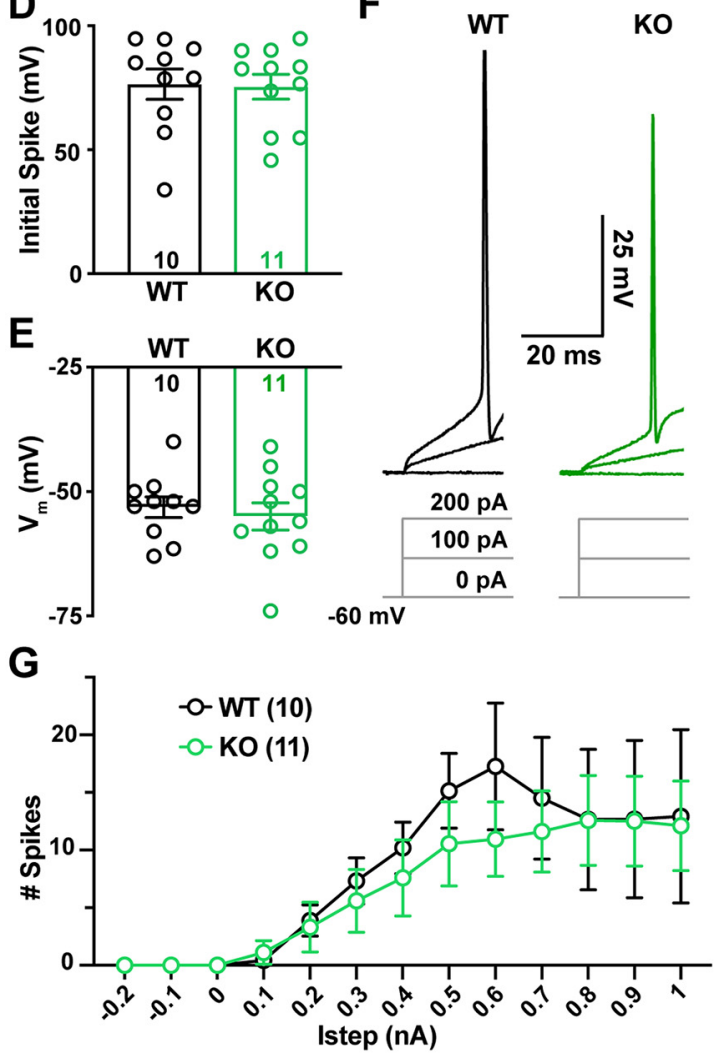

Figure 1. CF-evoked complex spikes (CpSs) are altered in the Cacna2d2 KO, but intrinsic PC excitability is unchanged. $\boldsymbol{A}$, Representative (F-evoked complex spikes in WT (left) and KO (right) PCs, arrow indicates CF stimulation. Each trace consists of 10 overlaid traces (lighter color) and the corresponding $\mathrm{CpS}$ average (dark color). $\boldsymbol{B}$, Average number of spikelets per C $\mathrm{pS}$ in WT and KO PCs; ${ }^{* *} p<0.01$ (Mann-Whitney). C, Percentage of spikelets exceeding $30 \mathrm{mV}$ trough-to-peak amplitude, ordered by spikelet number. $D$, Average ( $p$ S initial spike amplitude; $p=0.89$ (NS). $\boldsymbol{E}$, Average PC membrane potential when in zero current mode; $p=0.60$ (NS). $\boldsymbol{F}$, Representative single traces of membrane voltage responses to current injection, showing steps of 0,100, $200 \mathrm{pA}$ injections from $\mathrm{V}_{\mathrm{m}}=-60 \mathrm{mV}$; left, WT (black); right, $\mathrm{KO}$ (green). Average $I_{\text {step }}$ to initiate spiking $W T=200 \pm 39 \mathrm{pA}, n=10 ; \mathrm{KO}=289 \pm 82 \mathrm{pA}, n=9 ; p=$ 0.33 (NS). G, Average spike count during current steps from -0.2 to $1 \mathrm{nA}, \mathrm{V}_{\mathrm{m}}=-60 \mathrm{mV}$. WT (black) and KO (green); $p=0.63$ (NS; Two-way ANOVA with repeated measures, $F_{(1,19)}=$ $0.23)$. Data shown \pm SEM, $n=$ cells; unpaired Student's $t$ test unless otherwise indicated. 

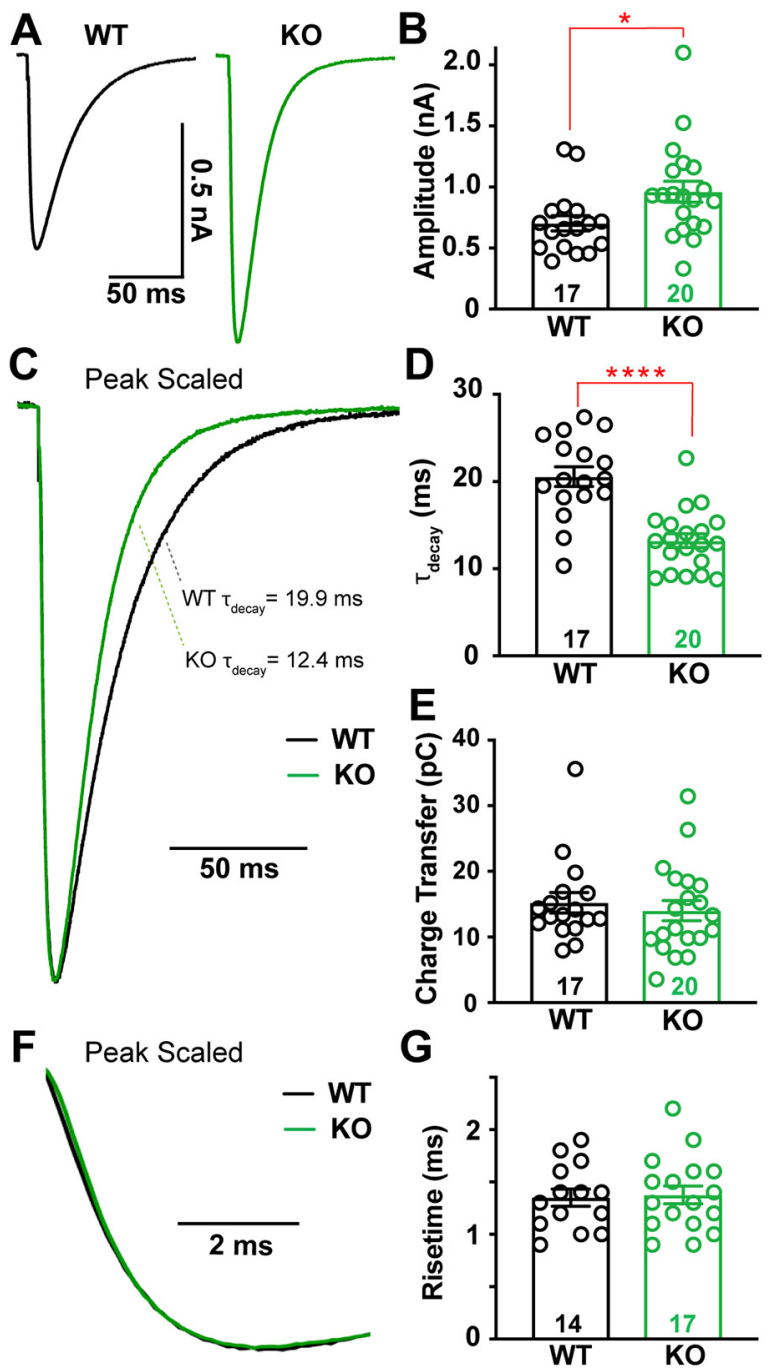

Figure 2. CF-evoked EPSCs are larger and faster in Cacna2d2 KO mice, but total charge transfer is conserved. $\boldsymbol{A}$, Representative (F-evoked EPSCs. Left, WT average (black); right, KO average (green). $\boldsymbol{B}$, Average peak CF EPSC amplitude; ${ }^{*} p<0.05$. C, Peak scaled EPSC, demonstrating the relative decay time constants for these example traces $\left(\tau_{\text {decay }}\right)$ based on single exponential fits; WT (black) and KO (green). D, $\tau_{\text {decay }}$ (ms) for CF EPSCs in WT vs KO PCs; $* * * * p<0.0001$. E, Average charge transfer within the first $100 \mathrm{~ms}$ of EPSC; $p=0.58$ (NS). $\boldsymbol{F}$, Peak scaled EPSCs, expanded to display risetime kinetics; WT (black) and KO (green). G, Average CF EPSC $20-80 \%$ risetime (ms); $p=0.83$ (NS). Data are shown as \pm SEM, $n=$ cells; unpaired Student's $t$ test.

resting membrane potentials (Fig. $1 E$ ), input resistance (WT $140 \pm 20 \mathrm{M} \Omega, n=8 ; \mathrm{KO} 122 \pm 7.8 \mathrm{M} \Omega, n=11 ; p=0.38$, unpaired Student's $t$ test), or response to current injection (Fig. $1 F, G)$. Thus, we explored whether altered CpS patterns might represent differences in CF-mediated synaptic currents.

\section{$\alpha 2 \delta$-2 KO mice have larger CF-evoked EPSCs with} accelerated decay kinetics

The kinetics of CF-evoked EPSCs influence the CpS shape, such that a slower EPSC decay increases the likelihood of spikelet generation (Rudolph et al., 2011). Spikelet generation is also sensitive to the peak synaptic conductance, as an increased phasic conductance can result in depolarization block and failure to generate spikelets (Davie et al., 2008). Thus, we performed whole-cell recordings of CF EPSCs in the presence of low concentrations of the $\alpha$-amino-3-hydroxy-5-methyl-4-isoxazolepropionic acid receptor (AMPAR) antagonist, NBQX $(0.5 \mu \mathrm{M})$, to facilitate voltage- clamp control (as in Dittman and Regehr, 1998; Liu and Friel, 2008; Rudolph et al., 2011).

Peak EPSC amplitudes were $37 \%$ larger in $\alpha 2 \delta$ - $2 \mathrm{KO}$ mice (Fig. $2 A, B$; WT $=703 \pm 63 \mathrm{pA}, n=17 ; \mathrm{KO}=961 \pm 86 \mathrm{pA}, n=$ $19, p=0.03$; unpaired Student's $t$ test). WT and KO EPSC decays were well fit by a single exponential curve with KO EPSCs exhibiting faster decay kinetics (Fig. $2 C, D$; WT $\tau_{\text {decay }}=20.6 \pm 1.1 \mathrm{~ms}$, $n=17 ; \mathrm{KO} \tau_{\text {decay }}=13.2 \pm 0.8 \mathrm{~ms}, n=20, p<0.0001$; unpaired Student's $t$ test). Despite these two alterations, the EPSC in the $\mathrm{KO}$ had an equivalent charge transfer to that of WT EPSCs (Fig. $2 E$ ), and $20-80 \%$ rise times were similar in WT and KO PCs (Fig. $2 F, G)$.

\section{Proximal redistribution of CF synapses in the $\alpha 2 \delta-2 \mathrm{KO}$ partially contributes to larger CF-evoked EPSCs}

To examine the larger EPSC in $\mathrm{KO}$ mice, we isolated quantal events at CF synapses by desynchronizing CF evoked release. We replaced extracellular calcium with strontium (Rudolph et al., 2011; Zhang et al., 2015), and measured the amplitudes of CFderived asynchronous quantal release events (aEPSCs). The average aEPSC was $24 \%$ larger in KO compared with WT PCs (Fig. $3 A-C ; \mathrm{WT}=25.6 \pm 1.0 \mathrm{pA}, n=8 ; \mathrm{KO}=31.8 \pm 1.6 \mathrm{pA}, n=8$, $p=0.004$; unpaired Student's $t$ test), indicating that part, but not all, of the increased CF-evoked EPSC amplitude could be accounted for by a larger unitary response.

Therefore, we asked whether there might also be an increase in the number of CF synapses onto PCs using an immunohistochemical approach. CF terminals can be selectively identified as discrete puncta along the primary dendrites of PCs through their expression of VGLUT2 (Miyazaki et al., 2004; Zhang et al., 2015). As is apparent in Figure $4 A$, VGLUT2 ${ }^{+}$puncta were closer to PC somata in $\mathrm{KO}$ mice than in WTs. CF terminals were a mean distance of $40.8 \pm 0.5 \mu \mathrm{m}$ from the PC soma in WT, whereas $\alpha 2 \delta$-2 KO mice had a mean CF terminal distance of $30.6 \pm 0.3$ $\mu \mathrm{m}$ (Fig. $4 A, C$; $n=3-5$ images from 5 mice of each genotype; $p<0.0001$; Kolmogorov-Smirnov test). Moreover, distal CF innervation (beyond $50 \mu \mathrm{m}$ from the PC soma; Fig. $4 B$ ) accounted for $23 \%$ of puncta in WT, but only $6 \%$ in KO. This shift in CF terminal distribution in $\mathrm{KO}$ animals was not associated with a change in VGLUT2 ${ }^{+}$puncta size (Fig. $4 D$ ) or overall number of puncta within the molecular layer (Fig. $4 E$; Mean number of puncta normalized to length of PCL: WT $=1.91 \pm 0.21$ puncta/ $\mu \mathrm{m}_{\mathrm{PCL}} ; \mathrm{KO}=1.81 \pm 0.14$ puncta $/ \mu \mathrm{m}_{\mathrm{PCL}}, n=3-5$ images from 5 mice of each genotype; $p=0.7$; unpaired Student's $t$ test). There was no change in the molecular layer width, and the density of PCs was unchanged (Mean molecular layer width; WT $=110 \pm$ $3.8 \mu \mathrm{m} ; \mathrm{KO}=106 \pm 4.8 \mu \mathrm{m}, p=0.43$; Mean PC density; WT $=$ $0.62 \pm 0.08$ cells $/ \mu \mathrm{m}_{\mathrm{PCL}} ; \mathrm{KO}=0.65 \pm 0.06$ cells $/ \mu \mathrm{m}_{\mathrm{PCL}}, p=$ $0.72 ; n=8$ images from 3 mice of each genotype; unpaired Student's $t$ test).

The more proximal location of CF inputs in the KO could contribute to both the increased EPSC amplitude and decay rate, due to decreased dendritic filtering (Roth and Häusser, 2001). To ask whether changes in CF synapse localization alone were sufficient to account for the altered EPSC amplitude and kinetics, we modified the Roth and Häusser (2001) computational model of dendritic integration of CF inputs onto PCs to match our data. This model, based on morphological reconstructions of single PCs and empirical measurements of dendritic filtering (Roth and Häusser, 2001), allowed us to simulate how redistribution of CF inputs would affect the ensemble CF EPSC. Using this model

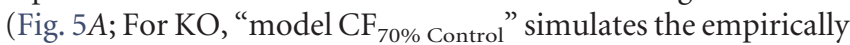
observed VGLUT2 ${ }^{+}$distribution from Fig. $4 C$ ), a shift from the 

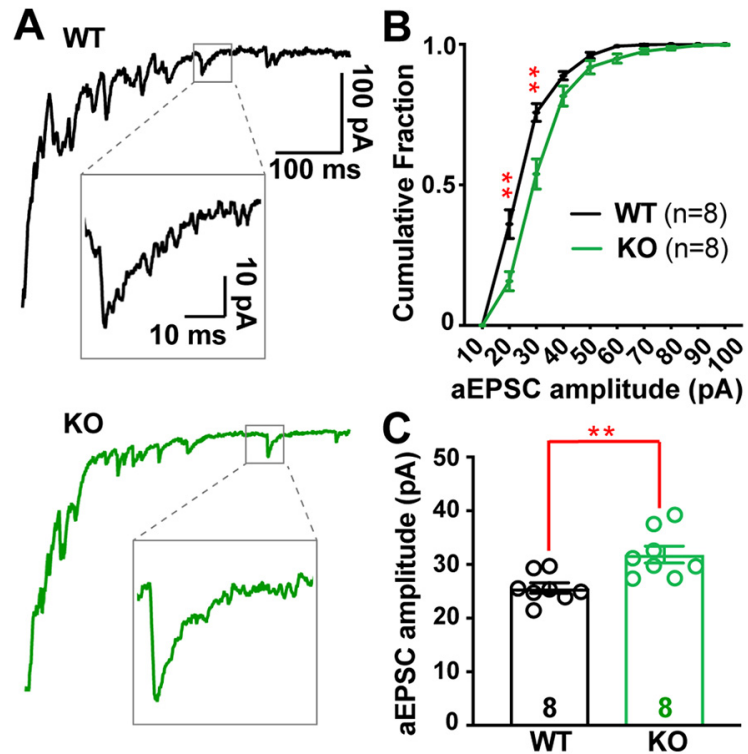

Figure 3. Desynchronized $(F-e v o k e d$ vesicle release reveals larger quantal responses in Cacna2d2 K0.A, Representative (F-evoked EPSCs in the presence of $1.3 \mathrm{~mm} \mathrm{Sr}^{2+}$; top, WT EPSC (black) and example asynchronous EPSC (aEPSC; inset); bottom, KO EPSC (green) and aEPSC (inset). $\boldsymbol{B}$, Cumulative aESPC amplitude distribution graphed in $10 \mathrm{pA}$ bins; WT (black) and K0 (green); ${ }^{* *} p<0.01$ for 20 and 30 pA bins, all others NS (multiple $t$ tests with Holm-Sidak correction for multiple comparisons). C, Average aEPSC amplitudes; ${ }^{* *} p<0.01$. Data are shown as \pm SEM, $n=$ cells; unpaired Student's $t$ test.

WT to the KO distribution of CF inputs produced a 16\% increase in simulated EPSC amplitude and a 15\% decrease in the decay time constant (Fig. 5B). Thus, the proximal distribution of $\mathrm{CF}$ inputs in the $\mathrm{KO}$ augment the quantal response (Fig. $5 \mathrm{C}$ ), to account for the increase in evoked CF EPSC amplitude.

\section{Increased multivesicular release from $\alpha 2 \delta$ - 2 KO CFs}

CF synapses exhibit multivesicular release, increasing the synaptic glutamate concentration (Wadiche and Jahr, 2001; Rudolph et al., 2011). To determine whether KO mice displayed altered multivesicular release, we used the low affinity, competitive AMPAR antagonist, kynurenic acid (KYN), to assay synaptic glutamate concentrations. Because KYN binds and unbinds AMPARs throughout the duration of the CF-evoked glutamate transient, KYN inhibition of the AMPAR-mediated current is inversely proportional to the concentration of glutamate present at postsynaptic receptors (Wadiche and Jahr, 2001). KYN (1 $\mu \mathrm{M})$ inhibited WT EPSC peak amplitudes by 65\% (Fig. 6A,B; EPSC $_{\text {Peak }}$ amplitude control vs $\mathrm{KYN} ; \mathrm{WT}_{\text {Control }}=1.77 \pm 0.41 \mathrm{nA}$ vs $\mathrm{WT}_{\mathrm{KYN}}=0.62 \pm 0.16 \mathrm{nA}, n=6, p=0.007$; paired Student's $t$ test), whereas KO EPSCs were inhibited by only $40 \%$ (EPSC $_{\text {Peak }}$ amplitude control vs $\mathrm{KYN} ; \mathrm{KO}_{\text {Control }}=2.63 \pm 0.31 \mathrm{nA}$ vs $\mathrm{KO}_{\mathrm{KYN}}$ $=1.57 \pm 0.21 \mathrm{nA}, n=8, p=0.0009$; paired Student's $t$ test; relative change in WT vs KO, $p=0.001$; unpaired Student's $t$ test), demonstrating enhanced multivesicular release from KO CFs.

For these experiments, PCs were held at $-20 \mathrm{mV}$ to maintain voltage clamp of the CF-evoked EPSC (Harrison and Jahr, 2003; Rudolph et al., 2011) and NBQX was omitted because coapplication of NBQX and KYN facilitates AMPAR-mediated responses (Prescott et al., 2006). Interestingly, at this holding potential, KO EPSCs exhibited slower decay kinetics (for $\tau_{\text {decay }}$ at baseline $V_{\mathrm{m}}=$ $-20 \mathrm{mV} ; \mathrm{WT}_{-20 \mathrm{mV}}=11.6 \pm 1.12 \mathrm{~ms}, n=6 ; \mathrm{KO}_{-20 \mathrm{mV}}=18.5 \pm$ $1.32 \mathrm{~ms}, n=8, p=0.002$; unpaired Student's $t$ test). Although this is consistent with a larger glutamate transient due to multi-
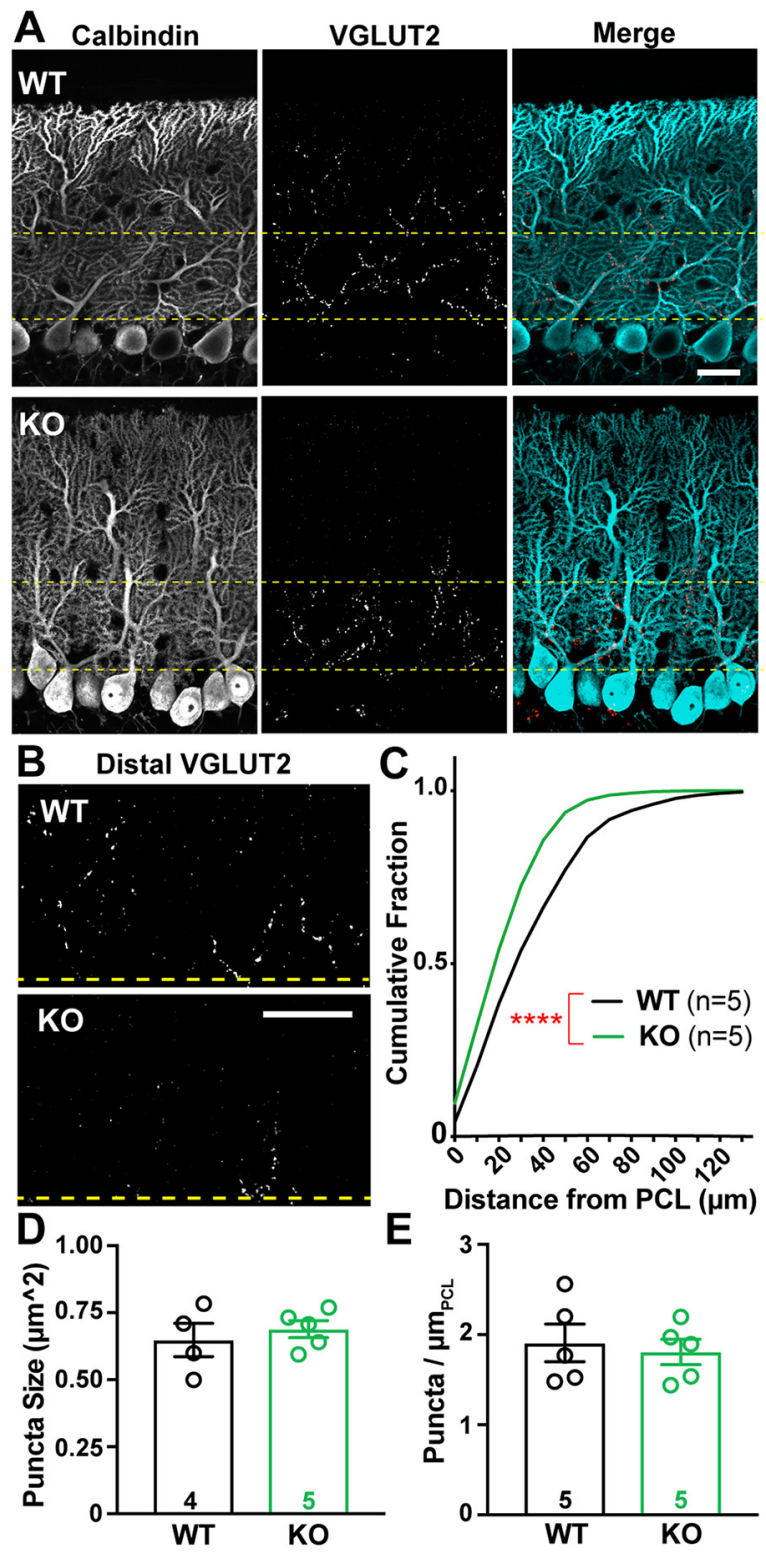

Figure 4. CF terminal distribution, but not number, is altered in Cacna2d2 KO cerebellum. $\boldsymbol{A}$ Representative images from p21 WT (above) and K0 (below) tissue, depicting the PCL. Calbindin (left/blue in merge) marks PCs, and VGLUT2 immunoreactivity (middle/red in merge) marks CF terminals. Yellow lines demarcate the $50 \mu \mathrm{m}$ most proximal to $\mathrm{PC}$ somata and is the region most highly innervated by climbing fibers. Scale bar, $20 \mu \mathrm{m}$. $\boldsymbol{B}$, VGLUT2-immunoreactive CF terminals in the outer molecular layer, cropped at the distal yellow line $(50 \mu \mathrm{m})$, illustrate differences in CF innervation of distal PC dendrites in WT (top) and KO (below) PCs. Scale bar, 20 $\mu \mathrm{m}$. C, Cumulative distribution of VGLUT2 ${ }^{+}$puncta relative to $\mathrm{PC}$ somas in WT (black, $n=5$ animals) and KO (green, $n=5$ animals); ${ }^{* * *} p<0.0001$ (Kolmogorov-Smirnov test). $\boldsymbol{D}$, Average VGLUT2 ${ }^{+}$punctum size was not significantly different between WT and K0 terminals; $p=0.55$ (NS). $E$, Average VGLUT2 ${ }^{+}$puncta density per length of $\mathrm{PCL}$ (puncta/ $\mu \mathrm{m}_{\mathrm{PCL}}$ ) was not significantly different between WT and KO; $p=0.72$ (NS). Unless otherwise stated, Data are shown as \pm SEM, $n=$ animal; unpaired Student's $t$ test.

vesicular release (Paukert et al., 2010), it is in apparent odds with the faster decay kinetics in KO PCs at more hyperpolarized potentials. One explanation for this discrepancy in decay kinetics could be the voltage dependence of glutamate reuptake by PCs. PCs and surrounding Bergmann glia express high levels of glutamate transporters to manage spillover and glutamate clearance, and activity of these transporters shapes the CF-evoked EPSC waveform (Paukert et al., 2010). However, PCs play a dominant 
A

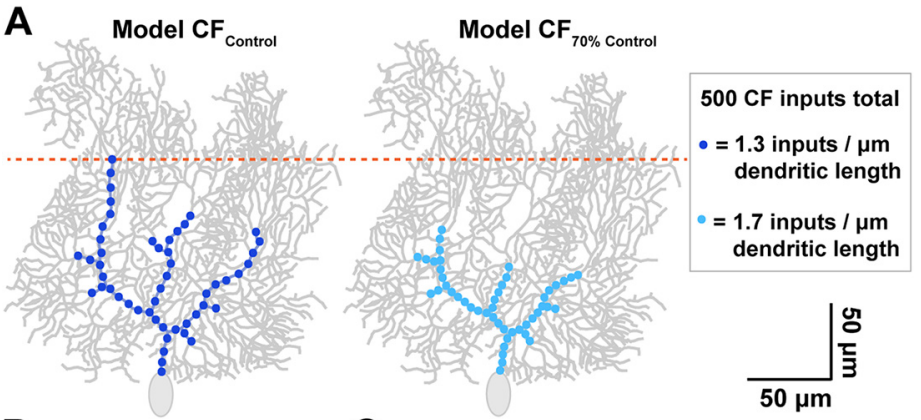

B

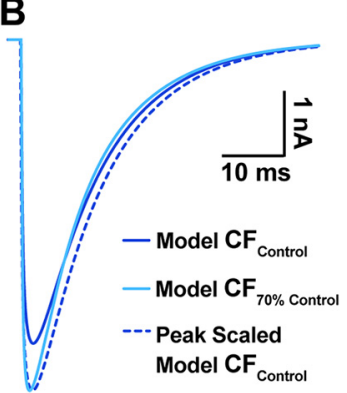

C

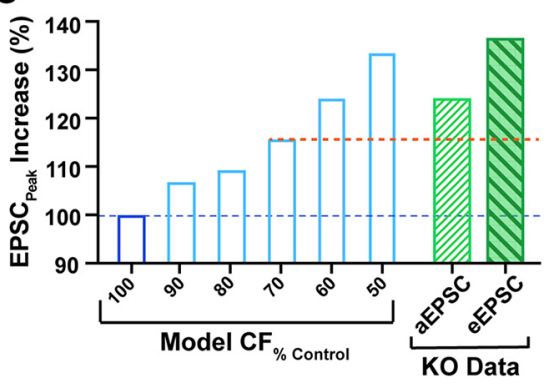

Figure 5. Computational $P C$ model simulates the impact of proximally shifted $C F$ inputs on EPSC waveform. $A$, Left, model CF input distribution similar to control PCs (dark blue; "model $\mathrm{CF}_{\text {Control }}$ ") vs a similar PC with CF inputs shifted $30 \%$ more proximal (right, light blue, "model $\mathrm{CF}_{70 \%}$ control"), which matches the degree of proximal shift in WT vs $\mathrm{KO}$ innervation, respectively. All models conserved the total number of $(F$ quantal inputs ( 500 inputs with $1 \mathrm{nS}$ conductance), though input density was adjusted to accommodate the shortened region of $\left(F\right.$ innervation (see inset). $B$, Overlay of EPSC output waveforms from model $\mathrm{CF}_{\text {Control }}$ simulations (dark blue; $4.7 \mathrm{nA}$ ), model $\mathrm{CF}_{70 \% \text { Control }}$ (light blue; $5.4 \mathrm{nA}$ ), and peak scaled model $\mathrm{CF}_{\text {Control }}$ to compare decay kinetics. For tau of decay; model $\mathrm{CF}_{\text {Control }} \tau_{\text {decay }}=12.0 \mathrm{~ms}$; model $\left.\mathrm{CF}_{70 \% \text { control }} \tau_{\text {decay }}=10.2 \mathrm{~ms}\right)$. C, Predicted increase in EPSC peak amplitude for various degrees of proximally shifted model CFs (light blue bars, restricted to a zone $100-50 \%$ the width of control (Fs, all including 500 quantal inputs) compared with model $\mathrm{CF}_{\text {Control }}$ (dark blue bar). For comparison, the empirically determined increase in quantal EPSC (aEPSC; hatched green bar) and evoked EPSC (eEPSC; filled-hatched dark green bar) amplitudes in KO PCS are also displayed (derived from Figs. 3 and 2, respectively). The orange dotted line demarcates the predicted EPSC increase from the model based on the observed shift in CF location.

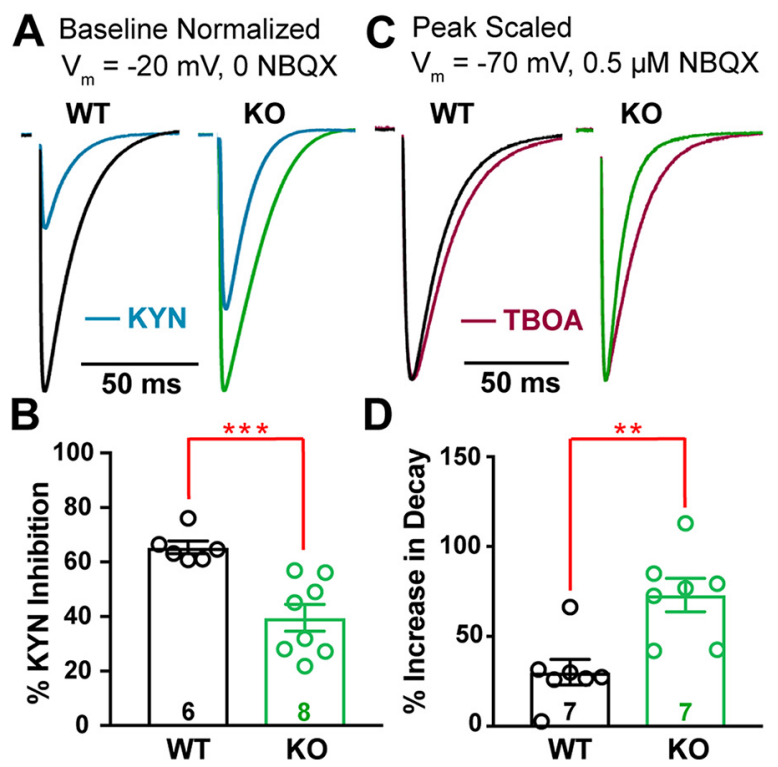

Figure 6. Cacna2d2 K0 has increased glutamate release and clearance at CF-PC synapses. $A$, Representative CF EPSCs recorded at $V_{m}=-20 \mathrm{mV}$ in the absence of NBQX for WT and KO PCs (relative scales; $\mathrm{WT}=$ black; $\mathrm{KO}=$ green). For each, traces after exposure to $1 \mathrm{~mm}$ kynurenic acid (KYN; blue) are shown normalized to baseline EPSC amplitudes. $\boldsymbol{B}$, Percentage inhibition of ESPC peak amplitude by KYN; ${ }^{* * *} p<0.001$. C, Representative normalized CF-evoked EPSCS recorded at $\mathrm{V}_{\mathrm{m}}=-70 \mathrm{mV}$ in the presence of $0.5 \mu \mathrm{M} \mathrm{NBQX}$; left, WT average (black); right, $\mathrm{KO}$ average (green). Overlay average peak-scaled traces after exposure to $50 \mu \mathrm{m}$ DL-TBOA (TBOA; magenta). $\boldsymbol{D}$, Average increase in EPSC decay by TBOA; ** $p<0.01$. Data are shown as \pm SEM, $n=$ cells; unpaired Student's $t$ test.

role in synaptic glutamate clearance (Auger and Attwell, 2000), and glutamate transporters have decreased efficiency at depolarized voltages (Bergles et al., 1997). In this scenario, the contributions of PC and Bergmann glia glutamate transporters together result in rapid EPSC decay in the $\mathrm{KO}$ at hyperpolarized potentials, but prolonged decay expected from multivesicular release dominates the EPSC waveform when KO PCs are held at depolarized potentials.

\section{Faster EPSC decay in $\alpha 2 \delta$ - 2 KO due to enhanced glutamate clearance}

We further investigated the role of glutamate transporters in shaping the CF EPSC waveform in WT and $\mathrm{KO}$ mice while holding PCs at $-70 \mathrm{mV}$ in the presence of low NBQX $(0.5 \mu \mathrm{M})$, as in our prior voltage-clamp experiments (Fig. 2). Block of glutamate transporters with the nonselective transport reuptake inhibitor, DLTBOA $(50 \mu \mathrm{M})$, increased WT decay constants by $\sim 30 \%$ (similar to Rudolph et al., 2011) (Fig. 6C; WT $\tau_{\text {decay }}$ control vs TBOA; $\mathrm{WT}_{\text {Control }}=13.6 \pm 0.9 \mathrm{~ms}$ vs $\mathrm{WT}_{\mathrm{TBOA}}=17.4 \pm 0.9 \mathrm{~ms}, n=7, p=$ 0.001; paired Student's $t$ test). In contrast, TBOA increased decay constants of KO EPSCs by $73 \%$ (KO $\tau_{\text {decay }}$ control vs TBOA; $\mathrm{KO}_{\text {Control }}=11.1 \pm 1.1 \mathrm{~ms}$ vs $\mathrm{KO}_{\mathrm{TBOA}}=19.1 \pm 2.2 \mathrm{~ms}, n=7, p=$ 0.001; paired Student's $t$ test). After TBOA exposure, WT and KO had similar decay constants $\left(\tau_{\text {decay }}\right.$ WT vs KO in TBOA; $p=0.48$; unpaired Student's $t$ test). However, the relative effect of TBOA on decay was greater in KO EPSCs (Fig. $6 D$; percentage increase in $\tau_{\text {decay }}$ $\mathrm{WT}$ vs $\mathrm{KO}, p=0.003$; unpaired Student's $t$ test) consistent with enhanced glutamate clearance by surrounding glutamate transporters.

Repetitive stimulation of CFs suggests lower release probability in the $\alpha 2 \delta-2 \mathrm{KO}$, though cumulative vesicle release is greater

The enhanced multivesicular release in the $\alpha 2 \delta$-2 KO (Fig. $6 A, B$ ) suggests a presynaptic contribution to the CF EPSC phenotype. CF synapses have high initial probability of release $\left(P_{\mathrm{R}}\right)$, which is associated with paired-pulse depression at short interstimulus intervals (Hashimoto and Kano, 1998). However, CF-evoked EPSCs from KO mice showed a consistent increase in the pairedpulse ratio when compared with WT CFs (Fig. $7 A, B$; pulse ratio: $\mathrm{WT}=0.41 \pm 0.03, n=17 ; \mathrm{KO}=0.51 \pm 0.02, n=18, p=0.01$; unpaired Student's $t$ test), suggesting CFs have a lower $P_{\mathrm{R}}$ when $\alpha 2 \delta$-2 is deleted. Therefore, we hypothesized that KO CFs might have a substantially greater readily releasable pool of vesicles to exhibit increased multivesicular release while also having a lower $P_{\mathrm{R}}$.

To estimate the relative size of the readily releasable pool in WT and $\mathrm{KO}$, we stimulated CFs with a $10 \mathrm{~Hz}$ train. WT and KO CF synapses had strikingly different responses during repetitive stimulation. Both genotypes exhibited a delayed facilitation followed by depression, which may indicate multiple pools of vesi- 


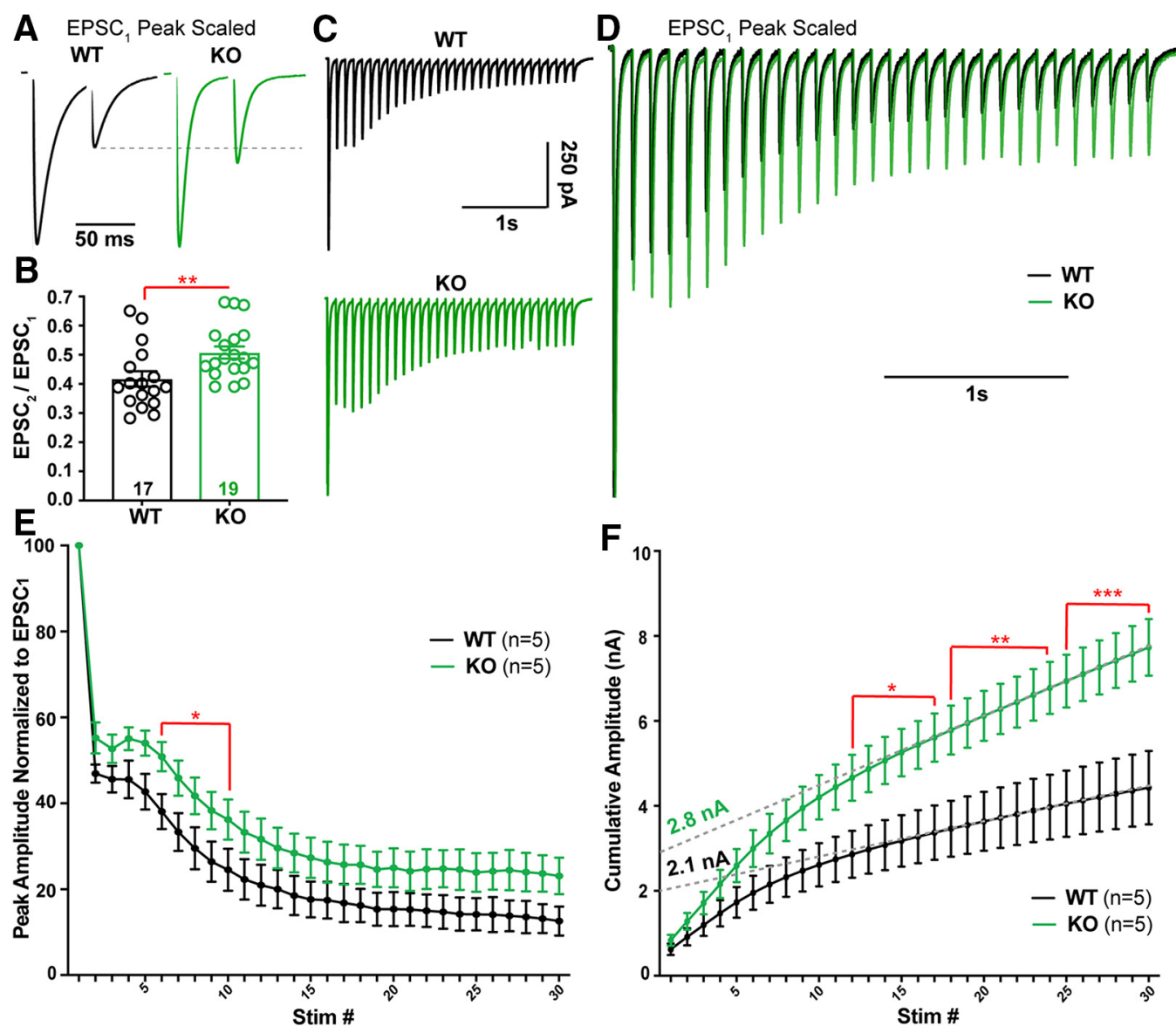

Figure 7. Repetitive stimulation of (F synapses reveals a lower probability of release and greater cumulative release in Cacna2d2 KO. A, Representative traces from WT (black) and KO (green) PCs during 50 ms paired-pulse stimulation. Traces are scaled to the first EPSC (EPSC $)$. Dotted gray line shows paired-pulse depression of the second EPSC (EPSC) in WT compared with KO. B, Average paired-pulse ratio (EPSC $2 / \mathrm{EPSC}_{1}$ ); ${ }^{* *} p<0.01$. C, Representative traces in response to $10 \mathrm{~Hz}$ stimulation; WT (black); KO (green). $\boldsymbol{D}$, Traces from (C) peak scaled to EPSC and overlaid, illustrating different relative steady-state EPSC amplitudes during latter portions of the train. E, Summary data of EPSC amplitudes normalized to EPSC during $10 \mathrm{~Hz}$ stimulation in WT (black) and KO (green). ${ }^{*} p<0.05$ (multiple t tests with Holm-Sidak correction). $\boldsymbol{F}$, EPSC amplitudes during $10 \mathrm{~Hz}$ stimulation plotted as cumulative amplitude from WT (black) and KO (green). For comparison of cumulative amplitude between WT and KO at various stimulation numbers (stim \#); ${ }^{*} p<0.05,{ }^{* *} p<0.01,{ }^{* * *} p<0.001$ (multiple $t$ tests with Holm-Sidak correction). Dotted gray lines illustrate a linear fit to cumulative amplitude between stim \# 20-30 from WT and K0 trains. Data are shown as \pm SEM, $n=$ cells; unpaired Student's $t$ test unless otherwise indicated.

cles with differing release probabilities (Lu and Trussell, 2016). However, KO EPSCs were larger at every stimulus throughout the train (Fig. $7 C-E$ ), providing further evidence of enhanced vesicle release compared with WT. A linear fit to the last 10 responses of a cumulative amplitude plot produced a steeper slope (Linear regression using 95\% Confidence Intervals; $\mathrm{WT}_{\text {slope }}=$ $78.7 \pm 0.6, n=5 ; \mathrm{KO}_{\text {slope }}=172.2 \pm 0.5, n=5 ; p<0.0001$; unpaired Student's $t$ test) and a larger $y$-intercept in KO PCs when compared with WT (Fig. $7 F$ ). This analysis provided an estimate of the readily releasable pool (Schneggenburger et al., 1999), which was $29 \%$ larger in the KO compared with WT (WT $y$-intercept $=2.08 \pm 0.02 \mathrm{nA}, n=5 ; \mathrm{KO} y$-intercept $=2.77 \pm$ $0.01 \mathrm{nA}, n=5 ; p<0.0001$; unpaired Student's $t$ test). Thus, both a single stimulus (Fig. $6 A, B$ ) and repetitive stimulation of CFs produced increased vesicle release in the $\alpha 2 \delta-2 \mathrm{KO}$, suggesting either an enhancement of a low $P_{\mathrm{R}}$ pool of vesicles ( $\mathrm{Lu}$ and Trussell, 2016) and/or more discrete release sites with reduced $P_{\mathrm{R}}$ compared with WT.

\section{CF terminals in $\alpha 2 \delta$ - 2 KO have more release sites}

Because we did not see an increased density of VGLUT2 ${ }^{+}$puncta by light microscopy, we hypothesized CF terminals in the KO had either a greater number of release sites or vesicles. CF terminals can be identified with electron microscopy (EM) by their high density of round synaptic vesicles (SVs) and contacts onto PC "thorns" along primary PC dendritic shafts (Palay and ChanPalay, 1974; Miyazaki et al., 2004). While blinded to genotype, we imaged and quantified CF terminals from WT and KO mice (10-15 images/animal; see Materials and Methods). In agreement with VGLUT2 ${ }^{+}$puncta size determined by confocal microscopy (Fig. 4D), CF terminal cross-sectional area was no different between genotypes when sampled using EM (Fig. $8 A, B)$. WT and KO CF terminals also had an equivalent density of SVs (Fig. 8C) and no change in number of SVs within $100 \mathrm{~nm}$ of the synaptic contact, a proxy for the readily releasable pool $\left(\mathrm{WT}=18.5 \pm 2.4 \mathrm{SV} / \mu \mathrm{m}_{\text {Contact }}, n=5\right.$ mice; $\mathrm{KO}=20.4 \pm 2.7$ $\mathrm{SV} / \mu \mathrm{m}_{\text {Contact }}, n=6$ mice, $p=0.6$; unpaired Student's $t$ test).

However, the number of synaptic contacts made by CF terminals in $\alpha 2 \delta$-2 KOs was nearly twice that of WT (Fig. $8 A, D$; WT $=$ $1.08 \pm 0.16$ contacts/terminal, $n=5$ mice; $\mathrm{KO}=2.08 \pm 0.17$ contacts/terminal, $n=6$ mice, $p=0.009$; Mann-Whitney test). Moreover, the distribution of the number of contacts made by $\mathrm{CF}$ terminals was right-shifted in $\mathrm{KO}$ (Fig. $8 E ; p<0.002$; Kolmogorov-Smirnov test). Although quantifying synaptic contacts per terminal using single EM sections likely underestimates the true number of contacts per terminal, the observed doubling of discrete contacts made by KO CFs is consistent with increased multivesicular release in the $\alpha 2 \delta-2 \mathrm{KO}$. 
A
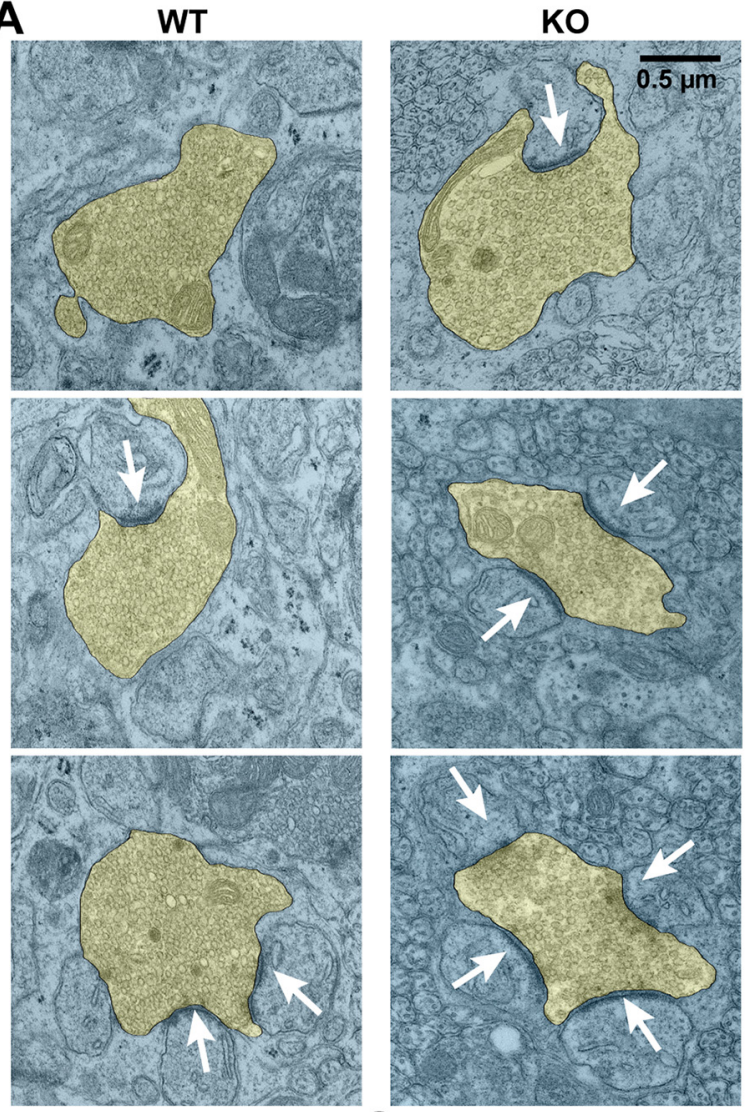

B

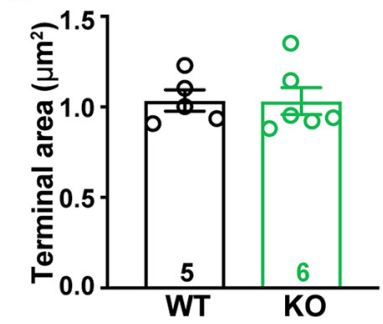

D
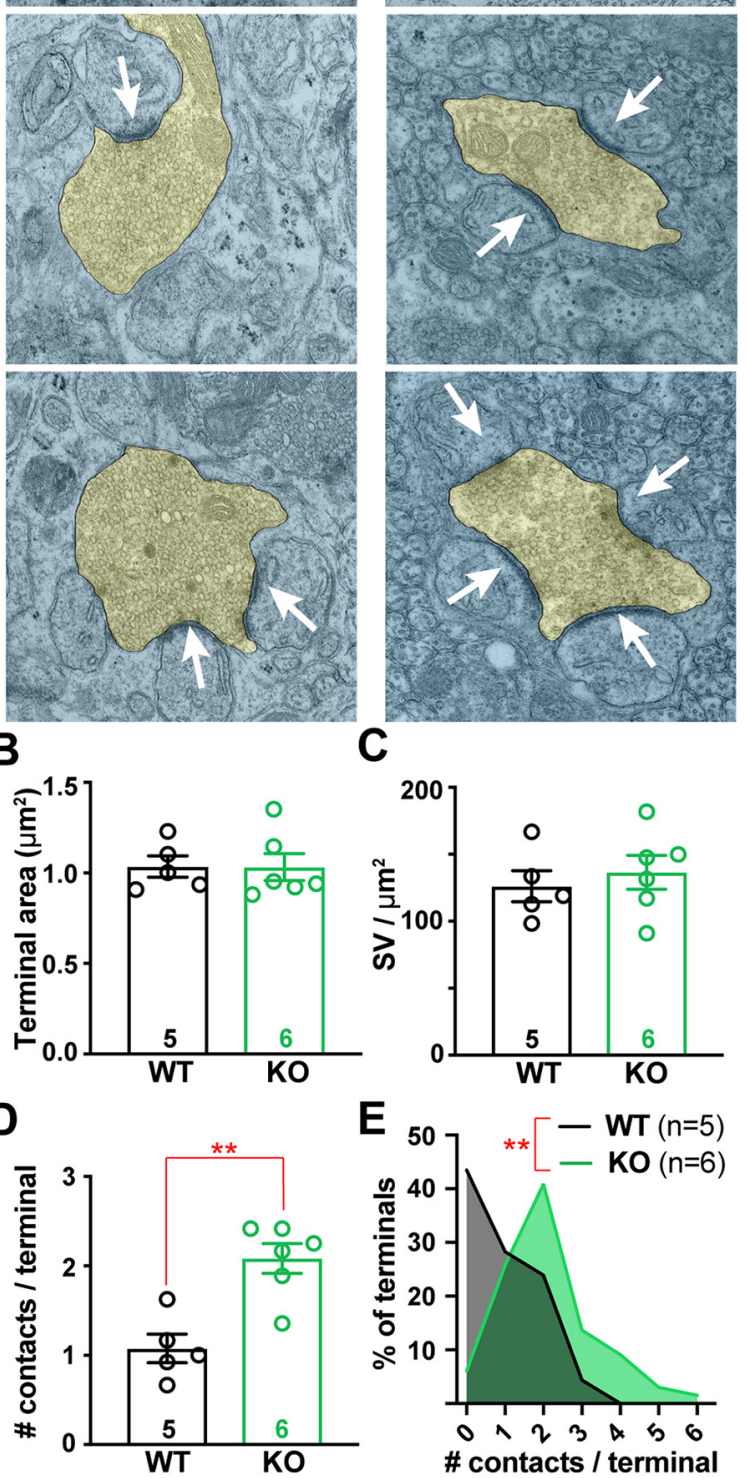

C

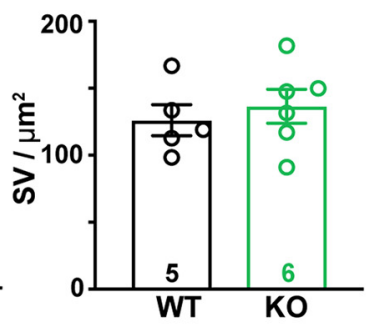

$\mathrm{E}$

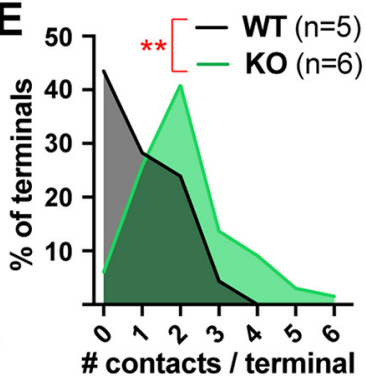

A

B

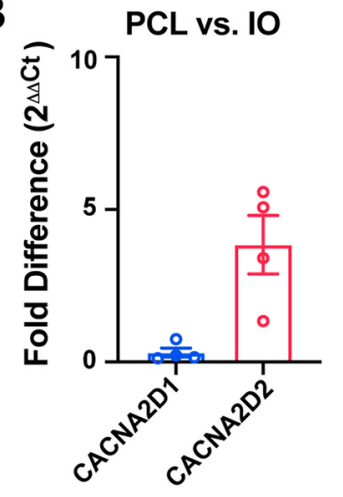

Figure 8. CF terminals have increased numbers of synaptic contacts in Cacna2d $2 \mathrm{~K} 0$ animals. $A$, Representative transmission electron micrographs of $\mathrm{CF}$ terminals (pseudocolored yellow) from p21 WT (left) and K0 (right) animals. White arrows indicate postsynaptic densities used to quantify synaptic contacts/terminal. Scale bar, $0.5 \mu \mathrm{m}$. B, Average CF terminal area $\left(\mu \mathrm{m}^{2}\right)$; $p=0.55$ (NS). C, Synaptic vesicle (SV) density (SV/ $\mu \mathrm{m}^{2}$ ) was not different between WT and KO animals; $p=0.57$ (NS). D, Average number of contacts per CF terminal (\# contacts/terminal) was increased in $\mathrm{KO}$ animals. ${ }^{* *} p<0.01$ (Mann-Whitney test). $\boldsymbol{E}$, Histogram of all CFs analyzed from WT (black) and KO (green) cerebella, displaying the number of contacts per sampled CF terminal normalized to total number of CF terminals; ${ }^{* *} p<0.01$ (Kolmogorov-Smirnov test). Data are shown as \pm SEM, $n=$ animals using $15-20$ images/animal; unpaired Student's $t$ test unless otherwise stated.
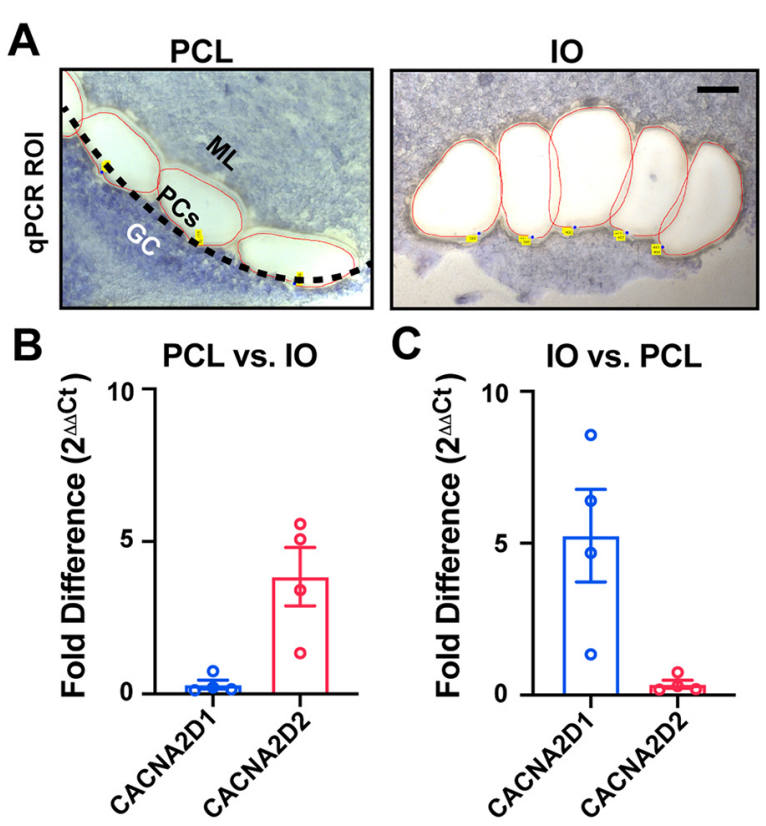

Figure 9. Relative expression of Cacna2d transcripts by qPCR from Purkinje cell layer (PCL) and inferior olive $(I 0)$ tissues. $A$, Example $P C L$ and $I 0$ regions of interest isolated by laser capture microdissection from fresh-frozen WT tissue. Left, PCL region of interest; black-dotted line indicates the monolayer of $\mathrm{PCS}$ that have been dissected along with regions of the inner molecular layer (ML; granule cells, GC). Right, 10 region of interest; one hemisphere from a coronal section of ventral brainstem, scale $=100 \mu \mathrm{m}$. $(B, C)$ Fold difference $\left(2^{-\Delta \Delta c t}\right)$ expression of Cacna2d is oforms by quantitative $P C R$ comparing $(B) P C L$ versus 10 , and $(C) I 0$ versus $P C L$ samples. Data are shown as $\pm \mathrm{SEM}, n=4$ animals.

Differential Cacna2d isoform expression in the IO and PCL

By in situ hybridization, there is robust and exclusive expression of the Cacna $2 d 2$ isoform in PCs, and relatively low expression in the inferior olive (IO), which gives rise to climbing fibers (Cole et al., 2005; Lein et al., 2007). Given the presynaptic morphological and physiological changes we observed at Cacna2d2 KO CF-PC synapses, we reexamined expression of $\alpha 2 \delta$ isoforms in the Purkinje cell layer (PCL) and IO using quantitative PCR of freshfrozen tissue obtained by laser capture microdissection (Fig. 9A). In agreement with prior observations (Cole et al., 2005; Lein et al., 2007), PCL tissue from WT mice expressed the $\alpha 2 \delta$ - 2 isoform $3.85 \pm 0.96$-fold higher than presynaptic IO samples (Fig. 9B; Cacna2d $2 \Delta \mathrm{Ct}_{\mathrm{PCL}}=1.62 \pm 0.17 ; \Delta \mathrm{Ct}_{\mathrm{IO}}=3.37 \pm 0.38, n=4, p=$ 0.03 ; paired Student's $t$ test). Importantly, analysis of Cacna2d transcripts from IO samples revealed that $\alpha 2 \delta$-1 is the predominant isoform in that region (Fig. $9 C$ ), and is $7.0 \pm 2.4$-fold more abundant than $\alpha 2 \delta$ - 2 in IO samples (Cacna2d1 $\Delta \mathrm{Ct}_{\mathrm{IO}}=0.94 \pm$ 0.4; Cacna2d $2 \Delta \mathrm{Ct}_{\mathrm{IO}}=3.37 \pm 0.38, n=4, p=0.04$; paired Student's $t$ test).

Our PCL samples contained other cell types found adjacent to PCs and within the proximal molecular layer, such as Bergmann glia and molecular layer interneurons. In situ hybridization experiments suggest that these cells, and not PCs, express $\alpha 2 \delta$-1 and/or $\alpha 2 \delta$-3 (Cole et al., 2005; Lein et al., 2007), which may explain the detection of low levels of $\alpha 2 \delta$-1 and a relatively high level of $\alpha 2 \delta-3$ mRNA in our PCL samples. Additionally, consistent with previous reports, $\alpha 2 \delta$ - 4 was undetectable in both the PCL and IO samples.

\section{Discussion}

In mice lacking $\alpha 2 \delta$-2, profound deficiencies in CF-induced complex spike $(\mathrm{CpS})$ generation were associated with altered 
underlying CF-evoked EPSC amplitude and kinetics. CpSs are initiated by a AMPAR-mediated depolarization that drives an initial sodium spike followed by multiple axonally generated 'spikelets' (Davie et al., 2008). Furthermore, dynamic clamp experiments suggested that increased CF EPSC amplitudes would result in depolarization block of spikelet generation (Davie et al., 2008). Thus, we hypothesize that increased glutamatergic transmission and accelerated EPSC kinetics (Rudolph et al., 2011) shape the CpS in the $\alpha 2 \delta$-2 KO (Fig. 10).

Each CF terminal in the KO contained more discrete synaptic contacts, leading to increased multivesicular release and consequently larger EPSCs, despite an apparent reduction in the probability of release. Together, these findings seem to contradict observations in which synapse formation is positively regulated by $\alpha 2 \delta$ expression (Li et al., 2004; Eroglu et al., 2009; Chen et al., 2018; Risher et al., 2018), reflecting a more complex and nuanced role of $\alpha 2 \delta$ proteins in the $\alpha 2 \delta$-2 KO phenotype.

$\alpha 2 \delta$-2 proteins as auxiliary $\mathrm{Ca}^{2+}$ channel subunits

$\alpha 2 \delta$ proteins were first identified as auxiliary subunits of voltage-dependent $\mathrm{Ca}^{2+}$ channels (VDCCs) that facilitate surface trafficking of VDCCs in heterologous expression systems (Cantí et al., 2005; Cassidy et al., 2014). $\alpha 2 \delta$-1 knockdown reduces presynaptic vesicle release in cultured hippocampal neurons (Hoppa et al., 2012), and capacitive measurements from inner hair cells of the spontaneous Cacna2d2 mutant $d u / d u$ show reduced exocytosis (Fell et al., 2016). We also observed a lowered $P_{\mathrm{R}}$ at the CF-PC synapse, as determined by paired-pulse ratio, which is consistent with these prior observations and could relate to altered VDCC localization or abundance in CFs. Given that $\alpha 2 \delta$-1 is the predominant isoform expressed by IO cells (Cole et al., 2005; Lein et al., 2007), if the phenotype we observed is mediated by presynaptic loss of $\alpha 2 \delta$-2, it suggests isoform-specific functions that cannot be compensated by $\alpha 2 \delta-1$. Furthermore, this raises the possibility that different $\alpha 2 \delta$ isoforms in individual neurons may have distinct functional roles.

In addition to their abundant $\alpha 2 \delta$ - 2 expression, PCs highly express the VDCC, Cav2.1 (Barclay et al., 2001), which localizes to PC somata and primary dendrites in scattered and clustered patterns (Indriati et al., 2013). Dissociated PCs from the spontaneous mutant, $d u^{2 j} / d u^{2 j}$, have $\sim 30 \%$ reduced somatic calcium currents (Barclay et al., 2001). Similarly, CF vesicle release is mostly (70-90\%) regulated by Cav2.1 (Regehr and Mintz, 1994). Because CF-PC transmission and development has been extensively characterized in Cav2.1 mutant mice (Matsushita et al., 2002; Miyazaki et al., 2004; Hashimoto et al., 2011), we looked to this literature for clues as to whether our observed phenotypes
KO

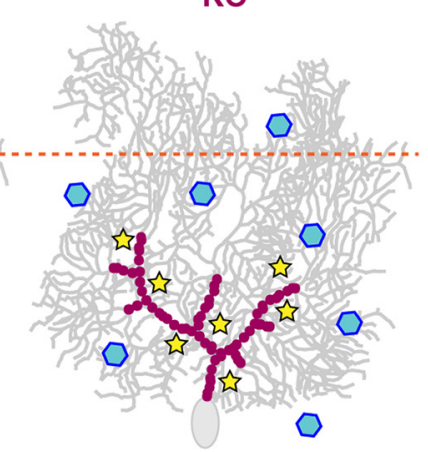

Outcomes

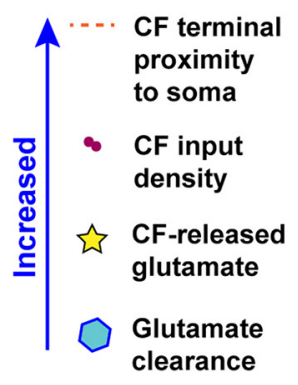

EPSC amplitude

EPSC decay rate

\section{CpS spikelet} generation

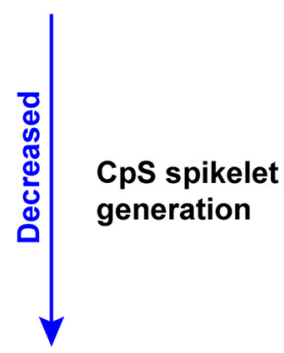

Figure 10. Summary of CF-PC phenotypes in Cacna2d2 KO mice. Proximal distribution of CF inputs onto KO PCs enhanced postsynaptic quantal responses to CF glutamate release, and the increased number of synaptic release sites increased total glutamate concentration. Together, this resulted in a 140\% EPSC amplitude in the K0 compared with control. Counteracting effects included a lower $C F P_{\mathrm{R}}$ and enhanced glutamate clearance, which doubled the EPSC decay rate. Ultimately, larger synaptic conductances in the KO likely contribute to depolarization block of CF-evoked spikelet generation.

could reflect altered pre- and/or postsynaptic VDCC function or localization.

For example, the leaner phenotype, in which a Cav2.1 pore mutation reduces $\mathrm{PC}$ calcium currents by $60 \%$, is associated with larger, rapidly decaying CF-evoked EPSCs (Liu and Friel, 2008), like the $\alpha 2 \delta$-2 KO. However, leaner CFs do not exhibit changes in $P_{\mathrm{R}}$ (Liu and Friel, 2008). Other Cav2.1 pore mutants show reductions in PC calcium current analogous to $\alpha 2 \delta$-2 mutants, but display heterogeneity in EPSC phenotypes. Both rolling Nagoya and tottering mutants have $40 \%$ reductions in calcium currents, yet rolling Nagoya exhibits larger, slowly decaying EPSCs, whereas tottering EPSCs are unchanged (Matsushita et al., 2002). PC-specific Cav2.1 KO show proximal innervation by CFs (Miyazaki et al., 2012), reminiscent of the CF redistribution we observed in Cacna2d2 KOs. This striking similarity provides evidence for postsynaptic control of CF development. Surprisingly however, global and PC-specific Cav2.1 KOs exhibit normal CF EPSC amplitude and decay kinetics (Miyazaki et al., 2004; Hashimoto et al., 2011). Thus, although some similarities exist between the Cacna2d2 KO and certain VDCC mutant mice, the roles of $\alpha 2 \delta$-2 at the CF-PC synapse likely involve other effector mechanisms. The phenotype of $\alpha 2 \delta$-2 loss may be more nuanced than altered VDCC abundance, but perhaps result from differ- 
ences in VDCC localization, clustering or association with other molecules (including other VDCC subtypes).

Altered presynaptic function could result from PC-driven morphological changes in the Cacna2d2 KO, independent of altered presynaptic VDCC trafficking. For example, alterations in presynaptic morphology alone, rather than altered presynaptic gene expression, can influence measures of apparent $P_{\mathrm{R}}$ and the readily releasable pool size by repetitive stimulation (Fekete et al., 2019). It is also possible that $P_{\mathrm{R}}$ at individual release sites is unchanged, but an increased number of release sites per terminal could allow for accumulation of $\left[\mathrm{Ca}^{2+}\right]_{\mathrm{i}}$ during repetitive stimulation via intersite crosstalk. In this scenario, repetitive stimuli recruit vesicles from a low $P_{\mathrm{R}}$ pool, sustaining release during subsequent stimuli. Currently, there is no definitive way to distinguish between a heterogeneous population of $P_{\mathrm{R}}$ at discrete release sites, or whether the vesicle recruitment from low vs high $P_{\mathrm{R}}$ pools differs (Kaeser and Regehr, 2017). The possibility of multiple vesicle pools in the $\mathrm{CF}$, as seen by the bimodal responses in Figure $7 C$, complicates our ability to derive readily releasable pool size and $P_{\mathrm{R}}$ at this synapse (Neher, 2015; Lu and Trussell, 2016). Given the various possible effector mechanisms for $\alpha 2 \delta$-2 that could contribute to the phenotype in mutant mice, further experiments using cell-type selective genetic manipulations will be necessary to fully understand the locus of $\alpha 2 \delta-2$ action.

\section{$\alpha 2 \delta$-2 proteins as synaptic organizers}

Recently, roles for $\alpha 2 \delta$ proteins independent of VDCCs are supported by their ability to regulate synapse formation despite pharmacological block or deletion of VDCCs (Eroglu et al., 2009; Kurshan et al., 2009). $\alpha 2 \delta$-1 induces excitatory synapse formation in response to glial-secreted thrombospondin (Eroglu et al., 2009), which is dependent on postsynaptic signaling through $\mathrm{N}$-methyl-D-aspartate receptors (NMDARs) (Risher et al., 2018). Though NMDARs are transiently expressed in newborn rat PCs (Rosenmund et al., 1992), they are not detected at mouse CF-PC synapses until late adulthood (Piochon et al., 2007; Renzi et al., 2007), making this interaction unlikely to contribute to the Cacna2d2 KO phenotype.

Studies in C. elegans suggest trans-synaptic roles for $\alpha 2 \delta$ proteins, as presynaptic $\alpha 2 \delta$-3 and binds to postsynaptic neurexin to control neuromuscular synaptic function (Tong et al., 2017). In mammals, neurexins are presynaptically expressed (Missler et al., 2003; Zhang et al., 2015) and interact trans-synaptically with postsynaptic neuroligins. Interestingly, similar to our observations in the Cacna2d2 KO, the neuroligin triple $\mathrm{KO}$ mouse (Zhang et al., 2015) also has a proximally shifted CF distribution, without a change in VGLUT2 ${ }^{+}$puncta size or overall density (Zhang et al., 2015). Although CF-PC synaptic function is unchanged in the neuroligin tKO (Zhang et al., 2015), this finding suggests that $\alpha 2 \delta$-2 may act in parallel with neurexin-neuroligin to coordinate features such as synaptic localization, whereas the functional components that depend on $\alpha 2 \delta$-2 involve other effector mechanisms.

The stereotyped development of the CF-PC synapse has made it an attractive model to study numerous important molecules that share mutant phenotypes, yet have quite disparate functions. For example, the CF innervation pattern is modulated by postsynaptically expressed neuroligins, TrkB, Cav2.1, GluR $\delta 2$ (exclusively expressed in PCs), cerebellins, and myosin $\mathrm{Va}$ (for review, see Bosman and Konnerth, 2009), revealing CF redistribution as a sensitive indicator of underlying dysfunction, and demonstrating postsynaptic control of synaptic innervation. Although Cacna2d2 KO mice share this phenotype, additional functional alterations at the $\mathrm{CF}-\mathrm{PC}$ synapse are dissimilar from other mutant mice. Thus, our data suggest that the contributions of $\alpha 2 \delta$-2 to the CF-PC synapse may comprise both VDCC-dependent and -independent mechanisms.

\section{Impacts of $\alpha 2 \delta$-2 loss on cerebellar function}

Of the four $\alpha 2 \delta$ isoforms (Cacna2d1-4), $\alpha 2 \delta$-2 loss has the most severe phenotype, as mice and humans with Cacna $2 d 2$ mutations have ataxia, epilepsy and motor control deficits (Barclay et al., 2001; Brodbeck et al., 2002; Ivanov et al., 2004; Donato et al., 2006; Pippucci et al., 2013). Because PCs provide the output from the cerebellum, some of these neurologic phenotypes likely reflect PC dysfunction. PC spike-rate and plasticity are instructed by $\mathrm{CpSs}$, providing error prediction information for motor coordination, presumably graded by the number of spikelets generated (Rasmussen et al., 2013; Yang and Lisberger, 2014; Burroughs et al., 2017). As CpSs generated by Cacna2d2 KO PCs had fewer spikelets, we predict PC information transfer is degraded, implicating direct influence of $\alpha 2 \delta$-2 loss in cerebellar dysfunction.

Particularly surprising was the variety of alterations at the Cacna2d2 KO CF-PC synapse, including enhanced glutamate reuptake. It is likely that some phenotypes developed as compensation for a primary derangement directly related to $\alpha 2 \delta-2$ loss. Delayed conditional deletion of $\alpha 2 \delta$ may help to clarify this issue. Likewise, deletion of $\alpha 2 \delta$-2 may have differential effects on other synapses and functions, either onto PCs or other cell types. As many neurons coexpress multiple $\alpha 2 \delta$ isoforms, it will be important to understand the role of each isoform at individual synapses, as well as address whether postsynaptic $\alpha 2 \delta$ proteins instruct presynaptic development or function (or vice versa), using cell-specific targeted rescue or deletion. Overall, our results underscore the critical roles of $\alpha 2 \delta$ - 2 in both proper organization and transmission at the CF-PC synapse.

\section{References}

Auger C, Attwell D (2000) Fast removal of synaptic glutamate by postsynaptic transporters. Neuron 28:547-558.

Barclay J, Balaguero N, Mione M, Ackerman SL, Letts VA, Brodbeck J, Canti C, Meir A, Page KM, Kusumi K, Perez-Reyes E, Lander ES, Frankel WN, Gardiner RM, Dolphin AC, Rees M (2001) Ducky mouse phenotype of epilepsy and ataxia is associated with mutations in the Cacna2d 2 gene and decreased calcium channel current in cerebellar Purkinje cells. J Neurosci 21:6095-6104.

Bergles DE, Dzubay JA, Jahr CE (1997) Glutamate transporter currents in bergmann glial cells follow the time course of extrasynaptic glutamate. Proc Natl Acad Sci U S A 94:14821-14825.

Bosman LW, Konnerth A (2009) Activity-dependent plasticity of developing climbing fiber-Purkinje cell synapses. Neuroscience 162:612-623.

Brockhaus J, Schreitmüller M, Repetto D, Klatt O, Reissner C, Elmslie K, Heine M, Missler M (2018) $\alpha$-neurexins together with $\alpha 2 \delta$ - 1 auxiliary subunits regulate $\mathrm{Ca}^{2+}$ influx through $\mathrm{Ca}_{\mathrm{v}} 2.1$ channels. J Neurosci 38:8277-8294.

Brodbeck J, Davies A, Courtney JM, Meir A, Balaguero N, Canti C, Moss FJ, Page KM, Pratt WS, Hunt SP, Barclay J, Rees M, Dolphin AC (2002) The ducky mutation in Cacna2d 2 results in altered Purkinje cell morphology and is associated with the expression of a truncated $\alpha 2 \delta-2$ protein with abnormal function. J Biol Chem 277:7684-7693.

Brown JP, Gee NS (1998) Cloning and deletion mutagenesis of the alpha2delta calcium channel subunit from porcine cerebral cortex. J Biol Chem 273:25458-25465.

Burroughs A, Wise AK, Xiao J, Houghton C, Tang T, Suh CY, Lang EJ, Apps R, Cerminara NL (2017) The dynamic relationship between cerebellar Purkinje cell simple spikes and the spikelet number of complex spikes. J Physiol 595:283-299.

Cantí C, Nieto-Rostro M, Foucault I, Heblich F, Wratten J, Richards MW, Hendrich J, Douglas L, Page KM, Davies A, Dolphin AC (2005) The metal-ion-dependent adhesion site in the von Willebrand factor-A do- 
main of $\alpha 2 \delta$ subunits is key to trafficking voltage-gated $\mathrm{Ca}^{2}+$ channels. Proc Natl Acad Sci U S A 102:11230-11235.

Cassidy JS, Ferron L, Kadurin I, Pratt WS, Dolphin AC (2014) Functional exofacially tagged $\mathrm{N}$-type calcium channels elucidate the interaction with auxiliary alpha2delta-1 subunits. Proc Natl Acad Sci US A 111: 8979-8984.

Chen J, Li L, Chen SR, Chen H, Xie JD, Sirrieh RE, MacLean DM, Zhang Y, Zhou MH, Jayaraman V, Pan HL (2018) The $\alpha 2 \delta$-1-NMDA receptor complex is critically involved in neuropathic pain development and gabapentin therapeutic actions. Cell Rep 22:2307-2321.

Cole RL, Lechner SM, Williams ME, Prodanovich P, Bleicher L, Varney MA, Gu G (2005) Differential distribution of voltage-gated calcium channel alpha-2 delta $(\alpha 2 \delta)$ subunit mRNA-containing cells in the rat central nervous system and the dorsal root ganglia. J Comp Neurol 491:246-269.

Davie JT, Clark BA, Häusser M (2008) The origin of the complex spike in cerebellar Purkinje cells. J Neurosci 28:7599-7609.

Dittman JS, Regehr WG (1998) Calcium dependence and recovery kinetics of presynaptic depression at the climbing fiber to Purkinje cell synapse. J Neurosci 18:6147-6162.

Dolphin AC (2012) Calcium channel auxiliary alpha2delta and beta subunits: trafficking and one step beyond. Nat Rev Neurosci 13:542-555.

Donato R, Page KM, Koch D, Nieto-Rostro M, Foucault I, Davies A, Wilkinson T, Rees M, Edwards FA, Dolphin AC (2006) The ducky(2J) mutation in Cacna2d 2 results in reduced spontaneous Purkinje cell activity and altered gene expression. J Neurosci 26:12576-12586.

Edvardson S, Oz S, Abulhijaa FA, Taher FB, Shaag A, Zenvirt S, Dascal N, Elpeleg O (2013) Early infantile epileptic encephalopathy associated with a high voltage gated calcium channelopathy. J Med Genet 50:118123.

Eroglu C, Allen NJ, Susman MW, O’Rourke NA, Park CY, Ozkan E, Chakraborty C, Mulinyawe SB, Annis DS, Huberman AD, Green EM, Lawler J, Dolmetsch R, Garcia KC, Smith SJ, Luo ZD, Rosenthal A, Mosher DF, Barres BA (2009) Gabapentin receptor alpha2delta-1 is a neuronal thrombospondin receptor responsible for excitatory CNS synaptogenesis. Cell 139:380-392.

Fekete A, Nakamura Y, Yang YM, Herlitze S, Mark MD, DiGregorio DA, Wang LY (2019) Underpinning heterogeneity in synaptic transmission by presynaptic ensembles of distinct morphological modules. Nat Commun 10:826.

Fell B, Eckrich S, Blum K, Eckrich T, Hecker D, Obermair GJ, Münkner S, Flockerzi V, Schick B, Engel J (2016) $\alpha 2 \delta 2$ controls the function and trans-synaptic coupling of Cav1.3 channels in mouse inner hair cells and is essential for normal hearing. J Neurosci 36:11024-11036.

Gao B, Sekido Y, Maximov A, Saad M, Forgacs E, LatifF, Wei MH, Lerman M, Lee JH, Perez-Reyes E, Bezprozvanny I, Minna JD (2000) Functional properties of a new voltage-dependent calcium channel. J Biol Chem 275:12237-12242.

Gee NS, Brown JP, Dissanayake VU, Offord J, Thurlow R, Woodruff GN (1996) The novel anticonvulsant drug, gabapentin (Neurontin), binds to $\alpha 2 \delta$ subunit of a calcium channel. J Biol Chem 271:5768-5776.

Geisler S, Schöpf CL, Stanika R, Kalb M, Campiglio M, Repetto D, Traxler L, Missler M, Obermair GJ (2019) Presynaptic $\alpha 2 \delta$-2 calcium channel subunits regulate postsynaptic GABAA receptor abundance and axonal wiring. J Neurosci 39:2581-2605.

Harrison J, Jahr CE (2003) Receptor occupancy limits synaptic depression at climbing fiber synapses. J Neurosci 23:377-383.

Hashimoto K, Kano M (1998) Presynaptic origin of paired-pulse depression at climbing fibre-Purkinje cell synapses in the rat cerebellum. J Physiol 506:391-405.

Hashimoto K, Ichikawa R, Kitamura K, Watanabe M, Kano M (2009) Translocation of a "winner" climbing fiber to the Purkinje cell dendrite and subsequent elimination of "losers" from the soma in developing cerebellum. Neuron 63:106-118.

Hashimoto K, Tsujita M, Miyazaki T, Kitamura K, Yamazaki M, Shin HS, Watanabe M, Sakimura K, Kano M (2011) Postsynaptic P/Q-type Ca ${ }^{2+}$ channel in Purkinje cell mediates synaptic competition and elimination in developing cerebellum. Proc Natl Acad Sci U S A 108:9987-9992.

Heffley W, Song EY, Xu Z, Taylor BN, Hughes MA, McKinney A, Joshua M, Hull C (2018) Coordinated cerebellar climbing fiber activity signals learned sensorimotor predictions. Nat Neurosci 21:1431-1441.

Hoppa MB, Lana B, Margas W, Dolphin AC, Ryan TA (2012) $\alpha 2 \delta$ expres- sion sets presynaptic calcium channel abundance and release probability. Nature 486:122-125.

Indriati DW, Kamasawa N, Matsui K, Meredith AL, Watanabe M, Shigemoto R (2013) Quantitative localization of Cav2.1 (P/Q-type) voltagedependent calcium channels in Purkinje cells: somatodendritic gradient and distinct somatic coclustering with calcium-activated potassium channels. J Neurosci 33:3668-3678.

Ivanov SV, Ward JM, Tessarollo L, McAreavey D, Sachdev V, Fananapazir L, Banks MK, Morris N, Djurickovic D, Devor-Henneman DE, Wei MH, Alvord GW, Gao B, Richardson JA, Minna JD, Rogawski MA, Lerman MI (2004) Cerebellar ataxia, seizures, premature death, and cardiac abnormalities in mice with targeted disruption of the Cacna2d2 Gene. Am J Pathol 165:1007-1018.

Kaeser PS, Regehr WG (2017) The readily releasable pool of synaptic vesicles. Curr Opin Neurobiol 43:63-70.

Khaliq ZM, Raman IM (2005) Axonal propagation of simple and complex spikes in cerebellar Purkinje neurons. J Neurosci 25:454-463.

Kurshan PT, Oztan A, Schwarz TL (2009) Presynaptic $\alpha 2 \delta$-3 is required for synaptic morphogenesis independent of its $\mathrm{Ca}^{2+}$-channel functions. Nat Neurosci 12:1415-1423.

Lein ES, Hawrylycz MJ, Ao N, Ayres M, Bensinger A, Bernard A, Boe AF, Boguski MS, Brockway KS, Byrnes EJ, Chen L, Chen L, Chen TM, Chin MC, Chong J, Crook BE, Czaplinska A, Dang CN, Datta S, Dee NR, et al. (2007) Genome-wide atlas of gene expression in the adult mouse brain. Nature 445:168-176.

Li CY, Song YH, Higuera ES, Luo ZD (2004) Spinal dorsal horn calcium channel alpha2delta-1 subunit upregulation contributes to peripheral nerve injury-induced tactile allodynia. J Neurosci 24:8494-8499.

Liu S, Friel DD (2008) Impact of the leaner P/Q-type $\mathrm{Ca}^{2+}$ channel mutation on excitatory synaptic transmission in cerebellar Purkinje cells. J Physiol 586:4501-4515.

Lu HW, Trussell LO (2016) Spontaneous activity defines effective convergence ratios in an inhibitory circuit. J Neurosci 36:3268-3280.

Matsushita K, Wakamori M, Rhyu IJ, Arii T, Oda S, Mori Y, Imoto K (2002) Bidirectional alterations in cerebellar synaptic transmission of tottering and rolling Ca2. J Neurosci 22:4388-4398.

Missler M, Zhang W, Rohlmann A, Kattenstroth G, Hammer RE, Gottmann K, Südhof TC (2003) Alpha-neurexins couple Ca21 channels to synaptic vesicle exocytosis. Nature 423:939-948.

Miyazaki T, Hashimoto K, Shin HS, Kano M, Watanabe M (2004) P/Q-type $\mathrm{Ca}^{2+}$ channel $\alpha 1 \mathrm{~A}$ regulates synaptic competition on developing cerebellar Purkinje cells. J Neurosci 24:1734-1743.

Miyazaki T, Yamasaki M, Hashimoto K, Yamazaki M, Abe M, Usui H, Kano M, Sakimura K, Watanabe M (2012) Cav2.1 in cerebellar Purkinje cells regulates competitive excitatory synaptic wiring, cell survival, and cerebellar biochemical compartmentalization. J Neurosci 32:1311-1328.

Neher E (2015) Merits and limitations of vesicle pool models in view of heterogeneous populations of synaptic vesicles. Neuron 87:1131-1142.

Palay SL, Chan-Palay V (1974) Cerebellar cortex: cytology and organization. Berlin: Springer.

Paukert M, Huang YH, Tanaka K, Rothstein JD, Bergles DE (2010) Zones of enhanced glutamate release from climbing fibers in the mammalian cerebellum. J Neurosci 30:7290-7299.

Piochon C, Irinopoulou T, Brusciano D, Bailly Y, Mariani J, Levenes C (2007) NMDA receptor contribution to the climbing fiber response in the adult mouse Purkinje cell. J Neurosci 27:10797-10809.

Pippucci T, Parmeggiani A, Palombo F, Maresca A, Angius A, Crisponi L, Cucca F, Liguori R, Valentino ML, Seri M, Carelli V (2013) A novel null homozygous mutation confirms CACNA2D2 as a gene mutated in epileptic encephalopathy. PLoS One 8:e82154.

Prescott C, Weeks AM, Staley KJ, Partin KM (2006) Kynurenic acid has a dual action on AMPA receptor responses. Neurosci Lett 402:108-112.

Rasmussen A, Jirenhed DA, Zucca R, Johansson F, Svensson P, Hesslow G (2013) Number of spikes in climbing fibers determines the direction of cerebellar learning. J Neurosci 33:13436-13440.

Regehr WG, Mintz IM (1994) Participation of multiple calcium channel types in transmission at single climbing fiber to Purkinje cell synapses. Neuron 12:605-613.

Renzi M, Farrant M, Cull-Candy SG (2007) Climbing-fibre activation of NMDA receptors in Purkinje cells of adult mice. J Physiol 585:91-101.

Risher WC, Kim N, Koh S, Choi JE, Mitev P, Spence EF, Pilaz LJ, Wang D, Feng G, Silver DL, Soderling SH, Yin HH, Eroglu C (2018) Thrombos- 
pondin receptor alpha2delta-1 promotes synaptogenesis and spinogenesis via postsynaptic Rac1. J Cell Biol 217:3747-3765.

Rosenmund C, Legendre P, Westbrook GL (1992) Expression of NMDA channels on cerebellar Purkinje cells acutely dissociated from newborn rats. J Neurophysiol 68:1901-1905.

Roth A, Häusser M (2001) Compartmental models of rat cerebellar Purkinje cells based on simultaneous somatic and dendritic patch-clamp recordings. J Physiol 535:445-472.

Rudolph S, Overstreet-Wadiche L, Wadiche JI (2011) Desynchronization of multivesicular release enhances Purkinje cell output. Neuron 70:9911004.

Schneggenburger R, Meyer AC, Neher E (1999) Released fraction and total size of a pool of immediately available transmitter quanta at a calyx synapse. Neuron 23:399-409.
Tong XJ, López-Soto EJ, Li L, Liu H, Nedelcu D, Lipscombe D, Hu Z, Kaplan JM (2017) Retrograde synaptic inhibition is mediated by alphaneurexin binding to the alpha2delta subunits of $\mathrm{N}$-type calcium channels. Neuron 95:326-340.e5.

Wadiche JI, Jahr CE (2001) Multivesicular release at climbing fiberPurkinje cell synapses. Neuron 32:301-313.

Wang T, Jones RT, Whippen JM, Davis GW (2016) $\alpha 2 \delta$-3 is required for rapid transsynaptic homeostatic signaling. Cell Rep 16:2875-2888.

Yang Y, Lisberger SG (2014) Purkinje-cell plasticity and cerebellar motor learning are graded by complex-spike duration. Nature 510: $529-532$.

Zhang B, Chen LY, Liu X, Maxeiner S, Lee SJ, Gokce O, Südhof TC (2015) Neuroligins sculpt cerebellar Purkinje-cell circuits by differential control of distinct classes of synapses. Neuron 87:781-796. 